\title{
High Yield of Adult Oligodendrocyte Lineage Cells Obtained from Meningeal Biopsy
}

\author{
Sissi Dolci't, Annachiara Pino ${ }^{1 t}$, Valeria Berton ${ }^{1 \dagger}$, Pau Gonzalez ${ }^{2}$, Alice Braga ${ }^{1}$, \\ Marta Fumagalli ${ }^{3}$, Elisabetta Bonfanti ${ }^{3}$, Giorgio Malpeli ${ }^{4}$, Francesca Pari ${ }^{1}$, \\ Stefania Zorzin', Clelia Amoroso', Denny Moscon', Francisco J. Rodriguez², \\ Guido Fumagalli', Francesco Bifari5* and Ilaria Decimo ${ }^{1 *}$
}

' Section of Pharmacology, Department of Diagnostics and Public Health, University of Verona, Verona, Italy, ${ }^{2}$ Group of Molecular Neurology, Hospital Nacional de Parapléjicos, Toledo, Spain, ${ }^{3}$ Laboratory of Molecular and Cellular Pharmacology of Purinergic Transmission, Department of Pharmacological and Biomolecular Sciences, University of Milan, Milan, Italy, ${ }^{4}$ Section of General and Pancreatic Surgery, Department of Surgery, Dentistry, Paediatrics and Gynaecology, University of Verona, Verona, Italy, ${ }^{5}$ Laboratory of Cell Metabolism and Regenerative Medicine, Department of Medical Biotechnology and Translational Medicine, University of Milan, Milan, Italy

\section{OPEN ACCESS}

Edited by:

Laura Helen Jacobson,

Florey Institute of Neuroscience and Mental Health, Australia

Reviewed by:

Gabriella Panuccio,

Istituto Italiano di Tecnologia, Italy Anusha Ande

University of Florida, United States

*Correspondence: Ilaria Decimo ilaria.decimo@univr.it

Francesco Bifar

francesco.bifari@unimi.it

tThese authors have contributed equally to this work.

Specialty section: This article was submitted to Translational Pharmacology, a section of the journal Frontiers in Pharmacology

Received: 17 July 2017 Accepted: 21 September 2017

Published: 12 October 2017

Citation

Dolci S, Pino A, Berton V, Gonzalez P, Braga A, Fumagalli $M$, Bonfanti E, Malpeli G, Pari F, Zorzin S, Amoroso C, Moscon D, Rodriguez FJ, Fumagalli G, Bifari F and Decimo I (2017) High Yield of Adult Oligodendrocyte Lineage Cells Obtained from Meningeal Biopsy. Front. Pharmacol. 8:703. doi: 10.3389/fphar.2017.00703
Oligodendrocyte loss can lead to cognitive and motor deficits. Current remyelinating therapeutic strategies imply either modulation of endogenous oligodendrocyte precursors or transplantation of in vitro expanded oligodendrocytes. Cell therapy, however, still lacks identification of an adequate source of oligodendrocyte present in adulthood and able to efficiently produce transplantable cells. Recently, a neural stem cell-like population has been identified in meninges. We developed a protocol to obtain high yield of oligodendrocyte lineage cells from one single biopsy of adult rat meningeal tissue. From $1 \mathrm{~cm}^{2}$ of adult rat spinal cord meninges, we efficiently expanded a homogenous culture of 10 millions of meningeal-derived oligodendrocyte lineage cells in a short period of time (approximately 4 weeks). Meningeal-derived oligodendrocyte lineage cells show typical mature oligodendrocyte morphology and express specific oligodendrocyte markers, such as galactosylceramidase and myelin basic protein. Moreover, when transplanted in a chemically demyelinated spinal cord model, meningeal-derived oligodendrocyte lineage cells display in vivo-remyelinating potential. This oligodendrocyte lineage cell population derives from an accessible and adult source, being therefore a promising candidate for autologous cell therapy of demyelinating diseases. In addition, the described method to differentiate meningealderived neural stem cells into oligodendrocyte lineage cells may represent a valid in vitro model to dissect oligodendrocyte differentiation and to screen for drugs capable to promote oligodendrocyte regeneration.

Keywords: oligodendrocyte precursor cells, meninges, meningeal neural stem cells, myelin, oligodendrocyte differentiation, adult neural stem cells, spinal cord

\section{INTRODUCTION}

Loss of oligodendrocytes in the CNS impairs neuronal transmission and increases neuronal frailty, eventually leading to cognitive and motor deficits (Karoutzou et al., 2007; Schmahmann et al., 2008; Duncan and Radcliff, 2016). The white matter of the adult CNS hosts a population of OPCs capable of generating myelinating oligodendrocytes in physiological conditions (Franklin and FfrenchConstant, 2008; Rivers et al., 2008; Nishiyama et al., 2009). OPCs retain a degree of remyelinating 
ability in disease (Decimo et al., 2012a): in response to demyelinating insults, OPCs are activated, increase their proliferation and migrate to demyelinated sites, where they start to restore myelin coverage (Picard-Riera et al., 2002; Powers et al., 2013). However, in case of persisting and excessive demyelinating pathological microenvironment, such as in MS, ischemic, and traumatic injuries, OPCs are progressively depleted and their remyelination efficiency decrease (Guest et al., 2005; Franklin and Ffrench-Constant, 2008; Shi et al., 2015; Traka et al., 2016).

Restoration of adequate oligodendrocyte cell number and function can be envisaged either by manipulation and stimulation of the endogenous OPC pool or by transplantation of oligodendrocytes (Franklin and Ffrench-Constant, 2008; Gallo and Deneen, 2014; Najm et al., 2015; Steinbeck and Studer, 2015). Currently, there are no successful therapies available to promote remyelination (Franklin and Ffrench-Constant, 2008), and several limitations prevent oligodendrocytes transplantation (Franklin, 2015; Trounson and McDonald, 2015; Goldman, 2016). Ideally indeed, oligodendrocytes source should have the following properties: (i) be of adult origin; (ii) be accessible for sampling; (iii) be easily expanded in vitro and (iv) be collected and transplanted, after cell expansion, in the same patient (named autologous setting) without causing major adverse effects. Different cell populations have been evaluated for regenerative purposes, including OPCs (Nishiyama et al., 1999), ESCs (Trounson and McDonald, 2015), iPSCs (BenDavid and Benvenisty, 2011), and olfactory-ensheathing cells (OECs) (Murrell et al., 2008). Endogenous OPCs have been identified as NG2-expressing cells in the adult CNS; however, they are scattered throughout in the brain and spinal cord parenchyma (Nishiyama et al., 1999). Therefore, NG2-derived OPC extraction from the patient own reservoir is inapplicable due to the extended tissue sample required to obtain a sufficient number of cells (Nishiyama et al., 1999; Franklin and FfrenchConstant, 2008; Schmahmann et al., 2008). On the other hand, ESCs are a potential unlimited source of oligodendrocytes. Ethical issues, however, raised by isolation from embryonic tissue together with the requirement of life-long immunosuppressive therapy for the transplant recipient, significantly compromise their clinical application (Trounson and McDonald, 2015). iPSCs are of adult origin and can efficiently differentiate into oligodendrocytes (Douvaras and Fossati, 2015) in large numbers; however, their clinical translation is dampened by their high risk of tumorigenicity (Ben-David and Benvenisty, 2011). Adult remyelinating cells from OECs represent a safer

Abbreviations: Aqp4, aquaporin 4; Cnp, 2',3'-cyclic-nucleotide $3^{\prime}$ phosphodiesterase; CNS, central nervous system; Dcx, doublecortin; EGF, epidermal growth factor; ESCs, embryonic stem cells; FGF2, human basic fibroblast growth factor; GalC, galactosylceramidase; GFAP, glial fibrillary acidic protein; iPSCs, induced-pluripotent stem cells; LFB, Luxol Fast Blue; LPC, lysophosphatidylcholine; MAP2/Mtap2, microtubule-associated protein 2; $\mathrm{MBP} / \mathrm{Mbp}$, myelin basic protein; MS, multiple sclerosis; NF160, neurofilament 160; NG2, chondroitin sulfate proteoglycan; NSCs, neural stem cells; OECs, olfactory ensheathing cells; OPCs, oligodendrocyte precursor cells; PDGF-AA, platelet-derived growth factor-AA; $\operatorname{PDGFR} \alpha$, platelet-derived growth factor receptor type $\alpha$; Plp1, proteolipid protein 1; SVZ, subventricular zone; Syt1, synaptotagmin 1; T3, 3,3', 5-triiodo-L-thyronine; Tub3, class III $\beta$ tubulin. alternative (Fouad et al., 2005), as they can be expanded in vitro and transplanted in autologous settings (Murrell et al., 2008). Clinical trials using these cell sources showed promising results in terms of safety of cells grafting (Chen et al., 2014). Nevertheless, the presence and degree of remyelination obtained using these cell sources have not been described yet (MackaySim et al., 2008). Overall, the identification of a cell source combining all these four properties (adult origin, accessible sampling, high yield of oligodendrocytes, and transplantable in an autologous setting) and that may represent a useful tool for high-throughput drug-screening assays for the identification of novel pharmacological targets for demyelinating disease is still under investigation (Franklin and Ffrench-Constant, 2008; Pino et al., 2017).

We described the presence of a pool of NSCs in rodent meninges (Bifari et al., 2009, 2015, 2017; Decimo et al., 2011, 2012a,b). Meningeal-resident NSCs display in vivo and in vitro gene expression properties similar to subventricular NSCs (Decimo et al., 2011; Bifari et al., 2017) and are able to migrate and differentiate into functional neurons in the neonatal cerebral cortex (Bifari et al., 2017). We described that cells with NSC features are present in meninges from the embryonic period up to adulthood (Bifari et al., 2009, 2015). Meningeal-resident NSCs can be cultured in vitro as neurospheres and differentiated into electrically functional neurons and oligodendrocytes (Bifari et al., 2009; Decimo et al., 2011). Considering the superficial localization of meninges on the CNS surface, adult meningeal-derived NSCs raise particular interest for their potential application in autologous cell transplantation and in vitro drug screening for demyelinating diseases. In this study, we developed a protocol to obtain high yield of remyelinating oligodendrocyte lineage cells from adult rat meningeal biopsy.

\section{MATERIALS AND METHODS}

\section{Organotypic Cell Culture}

Animal housing and all experimental procedures were approved by the Istituto Superiore di Sanità (I.S.S., National Institute of Health; protocol N. 154/2014-B, Italy) and the Animal Ethics Committee (C.I.R.S.A.L., Centro Interdipartimentale di Servizio alla Ricerca Sperimentale) of the University of Verona (Italy). Six to eight weeks old male and female SpragueDawley rats were anesthetized by intraperitoneal injection with chloral hydrate $(350 \mathrm{mg} / \mathrm{kg})$ and sacrificed by cervical dislocation. Spinal cord meninges were collected under a stereomicroscope and small samples of approximately $1 \mathrm{~cm}^{2}$ were isolated; then, tissue samples were washed in ice-cold HBSS and cultured into 6-wells plates in neurosphere expansion medium (NS, see section Media Compositions). Every 3-4 days, half of the medium (approximately $3 \mathrm{ml}$ ) was substituted with fresh NS medium. After 7-10 days, neurospheres were collected, centrifuged, mechanically dissociated to a singlecell suspension and further expanded in NS medium or cultured in oligodendrocyte-inducing Step Go1 medium (see below). 


\section{Media Compositions NS Medium}

Neurobasal medium (Thermo Fisher Scientific), 2\% B27 supplement (Thermo Fisher Scientific), 1\% N2 supplement (Thermo Fisher Scientific), $2 \mathrm{mM}$ glutamine (Thermo Fisher Scientific), $100 \mathrm{U} / \mathrm{ml}$ penicillin and $100 \mu \mathrm{g} / \mathrm{ml}$ streptomycin (Thermo Fisher Scientific), $20 \mathrm{ng} / \mathrm{ml}$ human EGF (PeproTech) and $20 \mathrm{ng} / \mathrm{ml} \mathrm{FGF2}$ (PeproTech).

\section{Step Go1 Medium}

Neurobasal medium, 2\% B27 supplement, $2 \mathrm{mM}$ glutamine, $100 \mathrm{U} / \mathrm{ml}$ penicillin and $100 \mu \mathrm{g} / \mathrm{ml}$ streptomycin, $20 \mathrm{ng} / \mathrm{ml}$ human FGF2 and $20 \mathrm{ng} / \mathrm{ml}$ human PDGF-AA (PeproTech).

\section{Step Go2 Medium}

Neurobasal medium, 2\% B27 supplement, $2 \mathrm{mM}$ glutamine, $100 \mathrm{U} / \mathrm{ml}$ penicillin and $100 \mu \mathrm{g} / \mathrm{ml}$ streptomycin, $20 \mathrm{ng} / \mathrm{ml}$ human FGF2, $5 \mathrm{ng} / \mathrm{ml}$ human PDGF-AA and $15 \mathrm{nM} \mathrm{3,3^{ \prime } , 5 -}$ triiodo-L-thyronine (T3) (Sigma-Aldrich).

\section{Step Go3 Medium}

Neurobasal medium, 2\% B27 supplement, $2 \mathrm{mM}$ glutamine, $100 \mathrm{U} / \mathrm{ml}$ penicillin and $100 \mu \mathrm{g} / \mathrm{ml}$ streptomycin, $5 \mathrm{ng} / \mathrm{ml}$ human PDGF-AA and $15 \mathrm{nM}$ T3.

\section{Oligodendrocyte Differentiation}

Single-cell suspensions, obtained from dissociated neurospheres, were cultured in Step Go1 medium to induce the differentiation into oligodendrocytes. After 7-10 days of culture, oligospheres are formed. Oligospheres were then dissociated into a single cell suspension and subsequently plated onto poly-D-lysine coated flasks for further 7-10 days in Step Go2 medium. After this period, Step Go3 medium was added for 3 days to prompt the differentiation process. At each of the four steps of oligodendrocyte differentiation we collected $\sim 100 \mathrm{k}$ cells for immunofluorescence and $\sim 500 \mathrm{k}$ cells for RT-PCR analyses.

\section{Immunofluorescence}

Cells were plated onto poly-D-lysine coated glass slides. Staining procedure was performed as previously described (Bifari et al., 2015; Lange et al., 2016). Briefly, following fixation in $4 \%$ paraformaldehyde (PFA, Sigma-Aldrich), aspecific binding sites were blocked by incubation in blocking solution (3\% fetal bovine serum, $1 \%$ bovine serum albumin, $0.3 \%$ Triton X-100 in PBS). Cells were incubated in primary antibody solution for $1.5 \mathrm{~h}$ at room temperature, washed thrice with blocking solution and incubated in the proper secondary antibody solution for $1 \mathrm{~h}$. After three washes in blocking solution, slides were incubated for $10 \mathrm{~min}$ with the nuclear dye TO-PRO3 (Thermo Fisher Scientific) and mounted on glass microscope slides for confocal microscope quantification (Zeiss LSM 710 confocal microscope).

Primary antibodies: nestin (mouse, 1:1000, BD Pharmingen, cat\# 556309), NG2 (rabbit, 1:1000, Merck-Millipore, cat\# AB5320), oligodendrocyte marker O4 (O4) (mouse, 1:200, Merck-Millipore, cat\# MAB345), oligodendrocyte marker O4 (O4) (mouse, 1:40, Sigma-Aldrich, cat\# O7139), MBP (rabbit,
1:500, Dako, cat\# A0623), MBP (mouse, 1:500, Sigma-Aldrich, cat\# AMAB91064), GalC (rabbit, 1:100, Merck-Millipore, cat\# AB142), NF160 (mouse, 1:200, Sigma-Aldrich, cat\# N5264).

\section{Image Analyses and Quantification}

To evaluate the oligodendroglial differentiation at each phase of the protocol, we performed immunofluorescence as described above. The positive-immunoreactive cells, for each marker, were determined using the ImageJ software (U.S. National Institutes of Health) as follow: (i) nestin positivity: cytoplasmatic elongated signal with single channel RGB color intensity $\geq 32$ (with minimum value $0=$ black; maximum value 255 = full color); (ii) NG2 positivity: cytoplasmatic elongated signal with single channel RGB color intensity $\geq 30$ (with minimum value 0 = black; maximum value $255=$ full color); (iii) $\mathrm{O} 4$ positivity: pointy signal in correspondence to the glycoprotein on membrane surface; (iv) MBP positivity: cytoplasmatic signal in cells with $\geq 3$ positive branches; (v) GalC positivity: cytoplasmatic signal with single channel RGB color intensity $\geq 50$ (with minimum value $0=$ black; maximum value $255=$ full color) and with $\geq 3$ positive branches. We quantified a minimum of 50 cells for each differentiation stage for each marker ( $n \geq 3$ independent samples). Data were expressed as percentage of positive cells/total number of counted $\left(\mathrm{TO}-\mathrm{PRO}^{+}\right.$) cells.

Cellular branches were manually counted for a minimum of 50 cells/sample/differentiation phase in blind quantification by three independent observers. Evaluation was performed on cells immunoreactive for MBP or GalC staining, which allowed visible identification of cellular branches, using the ImageJ software (U.S. National Institutes of Health). Data were expressed as mean number of branches/cell.

\section{NG2-Derived Oligodendrocyte Culture}

Primary NG2-derived oligodendrocytes were isolated from mixed glial cultures prepared from postnatal day (P) 2 Sprague-Dawley rat cortex by shaking cells on an orbital shaker at $200 \mathrm{rpm}$, as previously described (Fumagalli et al., 2011, 2015). NG2-derived OPCs were then collected and separated from microglia by incubation for $20 \mathrm{~min}$ on an uncoated petri dish. Purified NG2-derived OPCs were seeded onto poly-D,L-ornithine-coated glass coverslips $(50 \mu \mathrm{g} / \mathrm{ml}$, SigmaAldrich) in $60 \mathrm{~mm}$-dishes $(300 \mathrm{k}$ cells/dish) in Neurobasal with $2 \%$ B27, $2 \mathrm{mM}$ L-glutamine (EuroClone), $10 \mathrm{ng} / \mathrm{ml}$ human PDGF-BB (Sigma-Aldrich), and $10 \mathrm{ng} / \mathrm{ml}$ human FGF2 (Space Import Export), to promote proliferation. Cells were maintained in proliferation medium for 4 days and, then, shifted to a differentiating medium containing $10 \mathrm{ng} / \mathrm{ml}$ T3 (Sigma-Aldrich) for $72 \mathrm{~h}$. NG2-derived oligodendrocytes were lysed in $800 \mu$ l of TRIzol (Thermo Fisher Scientific).

\section{Quantitative Real-time RT (Reverse Transcription)-PCR Analysis (qRT-PCR)}

Cells were collected at each stage of the differentiation protocol for $n \geq 3$ replicates for $n \geq 2$ independent experiments. qRT-PCR 
was performed as previously described (Bifari et al., 2009) using the following primers (forward and reverse) or Taqman ${ }^{\mathrm{TM}}$ assays (Thermo Fisher Scientific):

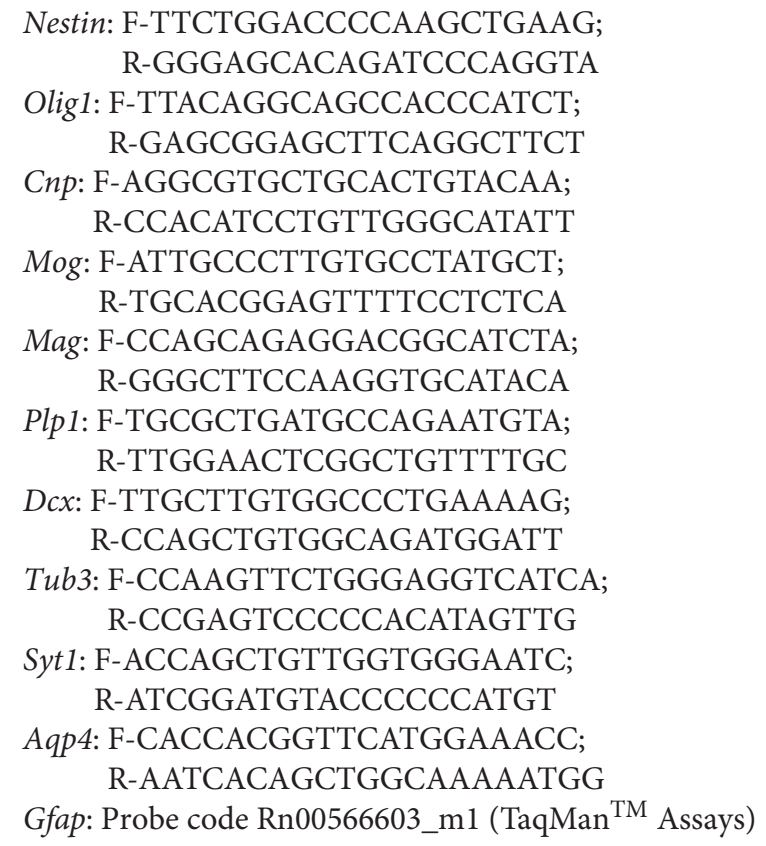

The mRNA levels of the housekeeping gene $\beta$-actin were used as reference to normalize the expression of the genes of interest.

Data are expressed as relative gene expression levels compared to undifferentiated meningeal-derived stem cells (NS).

\section{Meningeal-Derived Oligodendrocyte Lineage Cells Transplantation in Focal Demyelination Rat Model}

Animal housing and all experimental procedures were approved by the Bioethics Committee of The National Hospital of Paraplegics (Toledo, Spain). Three months old female Wistar rats, $\sim 300 \mathrm{~g}$ of weight $(n=6$ animals for the LPC-control group, $n=6$ animals for the LPC-transplanted group) were used. Rats were anesthetized with intraperitoneal injections of pentobarbital $(40 \mathrm{mg} / \mathrm{kg})$ and xylazine $(10 \mathrm{mg} / \mathrm{kg})$, the spinal cords were exposed by laminectomy at level of the T8 vertebra, and LPC ( $1 \%$ in saline solution) was injected at three points separated by $1 \mathrm{~mm}$ in the dorsal columns (2 $\mu \mathrm{l}$ at each point; $1 \mu \mathrm{l}$ at each 0.7 and $0.5 \mathrm{~mm}$ of depth). In each injection point, the solution was administered at a rate of $0.5 \mu \mathrm{l} / \mathrm{min}$ by using a $33 \mathrm{G}$ needle and a $10 \mu \mathrm{l}$ Hamilton syringe attached to a microinjector and a stereotaxic apparatus. The post-operative cares included subcutaneous injection of buprenorphine at 24 hours post injection (HPI) $(0.03 \mathrm{mg} / \mathrm{kg})$ and enrofloxacin $(2.5 \mathrm{mg} / \mathrm{kg})$ once daily until 5 days post injection (DPI). Moreover, animals received subcutaneous injections of saline solution for the first 5 DPI in decreasing doses, from $5 \mathrm{ml}$ at $24 \mathrm{HPI}$ to $1 \mathrm{ml}$ at 5 DPI.

In order to perform meningeal-derived oligodendrocyte lineage cells transplantation, LPC-demyelinated animals were divided in two groups, LPC-control (not transplanted) and LPC-transplanted (transplanted with meningealderived oligodendrocyte lineage cells). Meningeal-derived oligodendrocyte lineage cells, at Step Go2, were transduced with an eGFP-expressing lentiviral vector [10 multiplicity of infection (MOI)] for $16 \mathrm{~h}$. Spinal cords were again exposed at the T8 spinal level at $7 \mathrm{DPI}$, in order to inject vehicle (Neurobasal medium, LPC-control) or eGFP meningealderived oligodendrocyte lineage cells (LPC-transplanted). LPC-transplanted animals were injected with $2 \mu \mathrm{l}$ of Neurobasal medium containing 100'000 eGFP cells/ $\mu$ l, while LPC-control group received an injection of $2 \mu \mathrm{l}$ of Neurobasal medium. Injections were carried out at a rate of $0.5 \mu \mathrm{l} / \mathrm{min}$ using a $33 \mathrm{G}$ needle and a $10 \mu \mathrm{l}$ NanoFil syringe attached to a microinjector and a stereotaxic apparatus. In each injection point, the needle was maintained for five further minutes to minimize the reflux of the solution. The bladders were emptied twice daily until cardiac perfusion for histological analysis.

\section{Luxol Fast Blue Staining Protocol}

Myelin content was assessed in the tissue sections via LFB staining. Spinal cords from healthy control, LPC-control and LPC-transplanted animals were extracted after intracardiac perfusion with $4 \% \mathrm{PFA} / 4 \%$ sucrose and $25 \mu \mathrm{m}$-thick sections were cryosectioned. Sections from $1 \mathrm{~cm}$-rostral to $1 \mathrm{~cm}$ caudal to the lesion area were selected and used for analysis. First, $0.1 \%$ LFB solution was prepared solubilizing LFB (Sigma-Aldrich) in 95\% ethanol (EtOH, Carlo Erba) and $1.22 \%$ glacial acetic acid (Carlo Erba). Sections were hydrated in EtOH solutions (100, 95, 70, and 50\%), followed by staining with $0.1 \%$ LFB solution at $40^{\circ} \mathrm{C}$ for $40 \mathrm{~min}$. Sections were then rinsed with tap water and differentiated in $0.05 \% \mathrm{Li}_{2} \mathrm{CO}_{3}$ solution (Sigma-Aldrich). Sections were dehydrated in EtOH solutions (50, 70, 95, and 100\%), cleared in xylene (Carlo Erba) and mounted with Entellan (Merck-Millipore) for light microscopy analysis of myelin content (Zeiss Axioscop 2).

\section{Myelin Content Quantification}

After LFB staining, myelin content within the dorsal column of the spinal cords was quantified as percentage of the mean gray level within the dorsal column of each spinal cord slice (myelin positive pixels in the dorsal column/pixels of the total area of the dorsal column), using ImageJ software (U.S. National Institutes of Health). Blind quantification by three independent observers was performed to calculate the average value of the myelin content of healthy control, LPC-control and LPC-transplanted rats $(n \geq 20$ slices/animal; $n \geq 3$ animals/group).

\section{Statistical Analysis}

As described for each methodology, $n \geq 3$ animals or replicates were used for statistical analysis. Differences between experimental conditions were analyzed using two-way ANOVA followed by Tukey post-test. $P$-value $<0.05$ was considered statistically significant. 


\section{RESULTS}

\section{High Yield Oligodendrocytes from Rat Meningeal Biopsies: Development of a 4-Phases Oligodendrocyte Differentiation Protocol}

The possibility to perform in vitro patient-derived oligodendrocyte culture from adult somatic stem cells represents a potentially exploitable procedure for the identification of novel pharmacological targets for demyelinating disease and for high-throughput drug-screening assays (Franklin and FfrenchConstant, 2008; Pino et al., 2017). Furthermore, autologous cell transplantation is the gold standard approach for cell therapy. Isolation of high numbers of mature oligodendrocytes from living adult CNS represents one of the main obstacles in cell transplantation translation to the clinic. Two major issues need to be addressed for cell therapy to be exploited as potential autologous cell transplantation: first, the location and size of the tissue to be sampled; second, the time needed to obtain a large number of transplantable cells. To overcome the lack of accessible adult sources for production of oligodendrocytes, we set up a protocol to obtain oligodendrocyte lineage cells from one single biopsy of adult rat superficial meningeal tissue. We optimized the protocol in order to simultaneously maximize meningeal-derived oligodendrocyte lineage cell expansion and differentiation. We divided the protocol into four phases that comprehend changing ratios of mitogens and differentiating morphogens, allowing both oligodendrocyte precursor expansion and gradual maturation into oligodendrocyte lineage cells (Figure 1). To assess the progressive enrichment of differentiating oligodendrocytes in culture, we analyzed, at each phase of the protocol, the gene expression of: NSC marker Nestin (Figure 2A) (Lendahl et al., 1990), oligodendrocyte precursor marker Olig1 (Figure 2A) (Xin et al., 2005), and oligodendrocyte lineage markers coding for the major components of myelin sheaths Cnp (Figure 2B), myelin associated glycoprotein (Mag) (Figure 2B), myelin oligodendrocytes glycoprotein $(\mathrm{Mog})$ (Figure 2B), and Plp1 (Figure 2B) (Ranscht et al., 1982; Solly et al., 1996; Dugas et al., 2006; Cahoy et al., 2008).

\section{NS - Neurosphere Induction}

As for spinal cord central canal-derived NSCs, spinal cord meningeal-derived NSCs can be cultured in vitro and expanded as undifferentiated neurospheres (Weiss et al., 1996; Decimo et al., 2011). To obtain spinal cord meningeal-derived NSCs neurospheres, we sampled $1 \mathrm{~cm}^{2}$ biopsy of adult rat spinal cord meninges and cultured it directly, avoiding any mechanicalenzymatic procedure (Figure 1A). We used neurosphereinducing medium supplemented with growth factors known to induce NSCs proliferation, such as EGF and FGF2 (Martens et al., 2000) (refer to section Media Compositions for media composition). In this phase, single cells shed form the meningeal biopsy and then grow as neurospheres in culture. After 7-10 days of culture, we observed floating neurospheres (Figure 1B), which consisted of cells expressing the NSC marker nestin (Figure 2A) (Lendahl et al., 1990) as SVZ-derived and spinal cord-derived NSCs (as described in Weiss et al., 1996; Decimo et al., 2011). In addition, meningeal-derived neurospheres expressed the early oligodendrocyte precursor marker Olig1 (Figure 2A). We obtained approximately $2.5 \times 10^{5}$ undifferentiated meningeal-derived NSCs after 10 days of culture (Figure 1C).

\section{Step Go1-Oligodendrocyte Induction}

To induce oligodendrocyte precursors differentiation and expansion, we continued to culture NS-dissociated cells in the presence of the mitogen FGF2 and of the oligodendrocyte inducing morphogen PDGF-AA (McKinnon et al., 1990; Engel and Wolswijk, 1996; Calver et al., 1998) for 10 days (Figure 1B). In this culture condition, cells continue to growth as spheres, now referred as "oligospheres" (Figure 1B). The proliferation rate increased compared to the neurosphere expansion phase (Figure 1C).

\section{Step Go2 - Oligodendrocyte Differentiation and Proliferation}

Subsequently, to induce immature oligodendrocytes differentiation from oligodendrocyte precursors, we changed culture conditions by adding the oligodendrocyte-differentiating hormone 3,3',5-triiodo-L-thyronine (T3) (Almazan et al., 1985). To expand immature oligodendrocytes, we maintained in the medium the mitogens FGF2 and PDGF-AA, though PDGF-AA concentration was decreased (Figure 1B). Furthermore, to promote adhesion and extension of cellular processes typical of oligodendrocyte morphology (Baumann and Pham-Dinh, 2001), dissociated oligospheres were plated onto poly-D-lysine coated flasks and glass slides. After 7-10 days of culture in Step Go2 medium, we observed cells with branchings, suggesting a progression through oligodendrocyte lineage cells differentiation (Figure 1B). The immature oligodendrocytes statistically significantly decreased the expression levels of the stemness gene Nestin and of the oligodendrocyte precursor gene Olig1 (Figure 2A), while the expression of mature oligodendrocyte markers Cnp, Mag, Mog, and Plp1 (Ranscht et al., 1982; Campagnoni and Macklin, 1988; Cahoy et al., 2008) slightly increased (Figure 2B). In this culture condition, while inducing specific oligodendrocyte differentiation, we further promoted oligodendrocytes expansion and we were able to expand the cells $\sim 14$-fold (Figure 1C).

\section{Step Go3 - Oligodendrocyte Terminal Differentiation}

To promote the final differentiation from immature oligodendrocytes to mature oligodendrocyte lineage cells, we removed the mitogen FGF2 from the medium, while maintaining the morphogens PDGF-AA and T3 (Figure 1B). After only 3 days of culture in Step Go3 medium, meningealderived oligodendrocyte lineage cells formed a dense network of fine processes typical of cultured mature oligodendrocytes (Figure 1B).

Gene expression analysis confirmed terminal oligodendrocyte differentiation, as shown by the upregulation of myelinspecific genes (Dugas et al., 2006) Plp1, ( 130-fold increase, $p<0.001$ for Step Go3 vs. NS relative expression levels), 
A

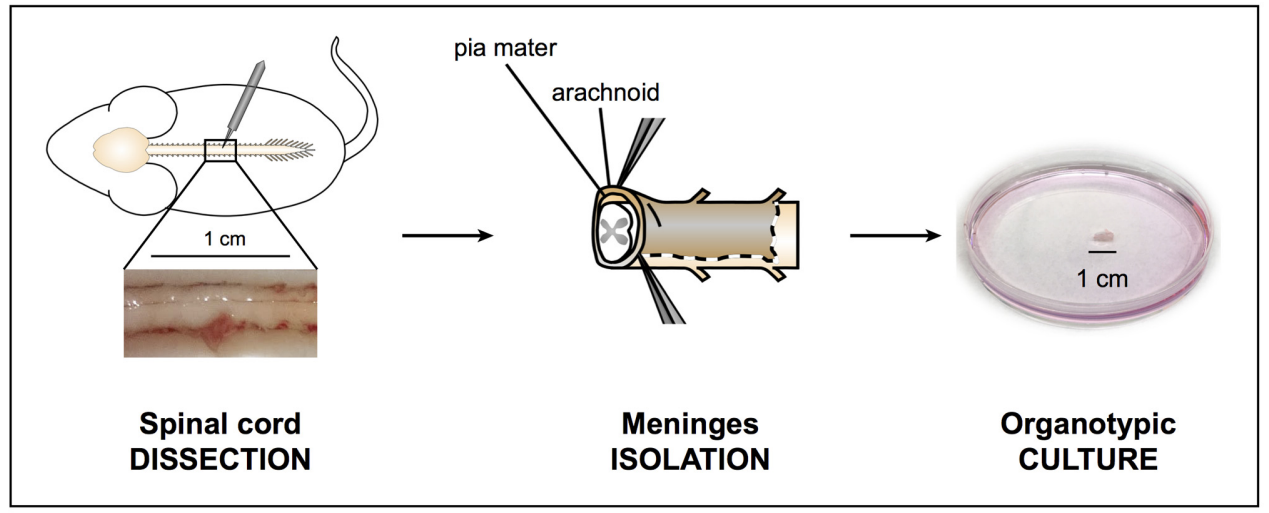

B

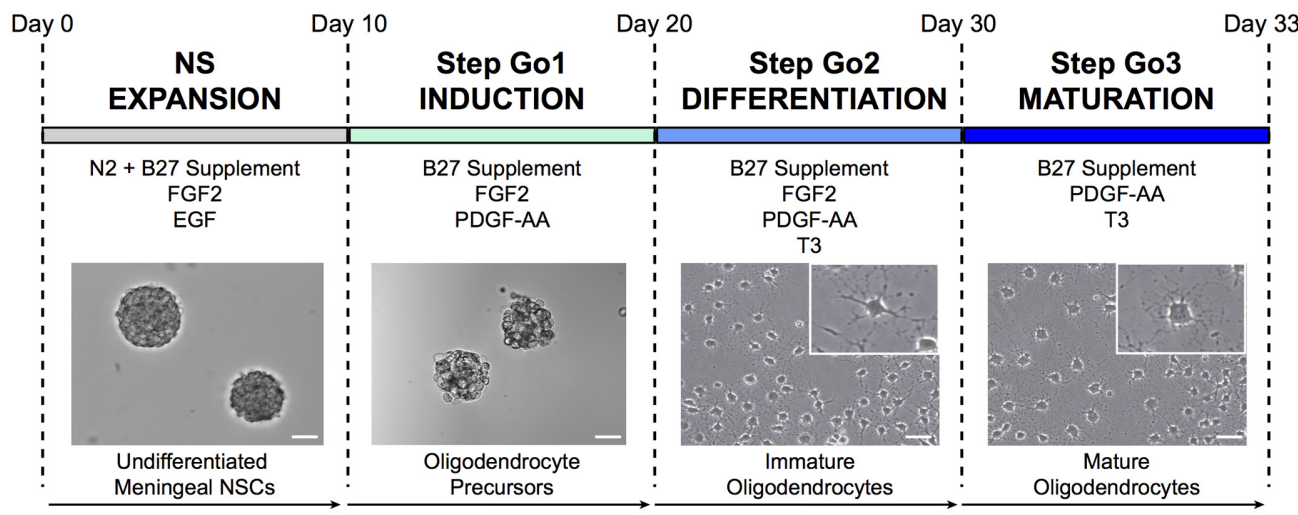

C

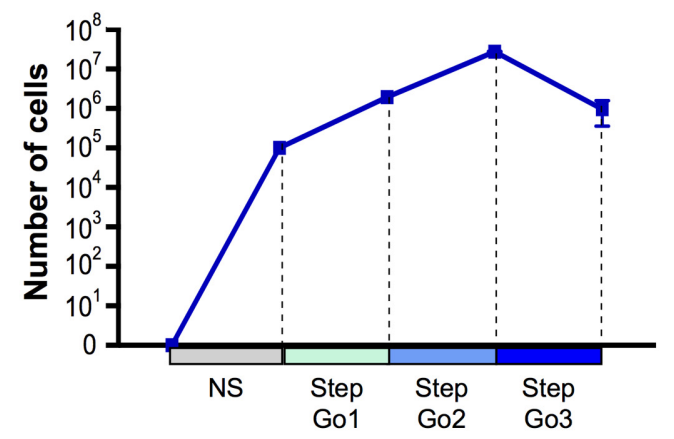

FIGURE 1 | Oligodendrocyte differentiation protocol. (A) Schematic representation of spinal cord meningeal biopsy isolation for organotypic culture. Spinal cord was dissected from adult SD rat and $1 \mathrm{~cm}$ of meningeal tissue was isolated and plated in neurosphere expansion medium (NS, day 0). (B) Time course representation of the oligodendrocyte differentiation protocol from spinal cord meningeal biopsy. From day 0 to day 10: neurosphere expansion (NS), from day 10 to day 20 : oligosphere culture (Step Go1); from day 20 to day 30: oligodendrocyte differentiation (Step Go2); from day 30 to day 33: oligodendrocyte maturation (Step Go3). Images show meningeal-derived differentiating oligodendrocyte morphology at each stage of the protocol. Insets in (B) are higher magnification images of representative cells in the boxes. Pictures in (B) are brightfield images. (C) Number of meningeal-derived cells in culture, calculated for every experimental replicate $(n=4)$, present at each stage of the differentiation protocol. Data are presented as mean \pm SEM. NSCs: neural stem cells; FGF2: human basic fibroblast growth factor; EGF: epidermal growth factor; PDGF-AA: platelet-derived growth factor type AA; T3: 3,3',5-triiodo-L-thyronine. Scale bars: $50 \mu \mathrm{m}$.

as well as a 8 -fold increase of $\operatorname{Cnp}(p<0.001$ compared to NS), 56-fold increase of Mag ( $p<0.001$ compared to NS) and 76-fold increase of $\operatorname{Mog}(p<0.01$ compared to NS) (Figure 2B).
To confirm that meningeal-derived oligodendrocyte lineage cells expressed the same oligodendrocyte markers of mature oligodendrocytes, we analyzed the oligodendrocyte marker expression of NG2-derived mature oligodendrocytes 
A

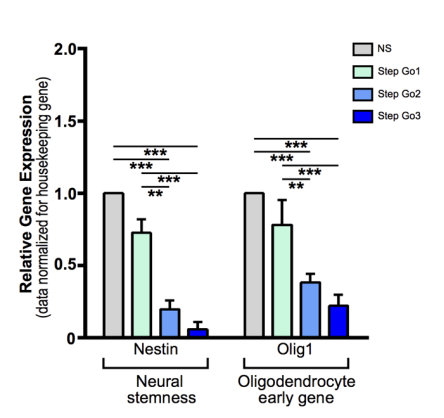

C

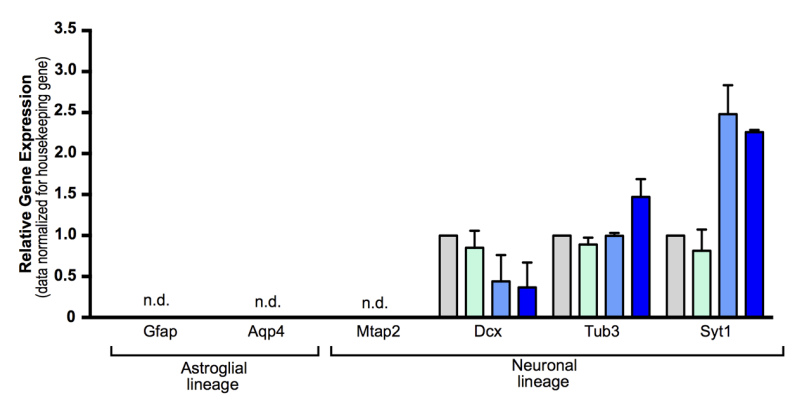

B
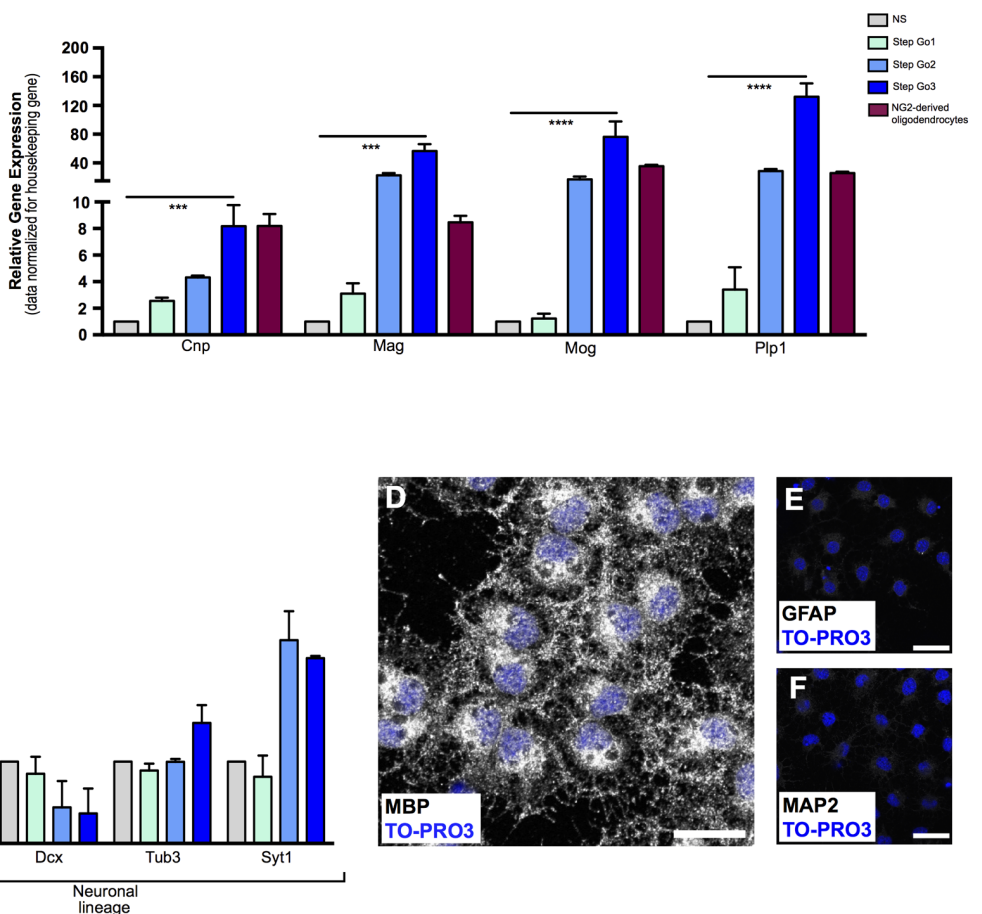

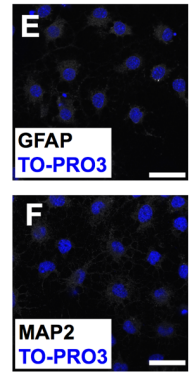

FIGURE 2 | Gene and protein analysis confirms differentiation of meningeal-derived NSCs into oligodendrocytes. (A) Relative gene expression analysis of meningeal-derived oligodendrocyte lineage cells shows significant decrease of the neural-stemness-related gene Nestin and the oligodendrocyte-specification gene Olig1 through the oligodendrocyte differentiation protocol. (B) Relative gene expression analysis of oligodendrocytes specific genes Cnp, Mag, Mog, and Plp1 in meningeal-derived differentiating oligodendrocytes at each step of the differentiation protocol and in NG2-derived oligodendrocytes. As expected, Step Go3 meningeal-derived oligodendrocyte lineage cells show significant increase of oligodendrocyte specific genes compared to meningeal-derived cells in NS. (C) Gene expression analysis of specific astroglial lineage genes (Gfap and Aqp4) and neuronal lineage genes, (Mtap2, Dcx, Tub3, and Syt1) in meningeal-derived differentiation oligodendrocytes at each step of the differentiation protocol. Gfap, Aqp4, and Mtap2 were not expressed at any step of the differentiation protocol, and were detected only after a high number of cycles (mean $\Delta C_{t}: 17.2 \pm 2.13$ Gfap, $14.7 \pm 1.66$ Aqp4, and 13.89 \pm 0.7 Mtap2). Dcx, Tub3, and Syt1 were expressed at lower level during all steps of the differentiation protocol. Gene expression levels were normalized to those of the housekeeping gene $\beta$-actin and are expressed as normalized to basal conditions (NS). (D-F) Immunofluorescence analysis, showing that by the end of the protocol the majority of the meningeal-derived oligodendrocytes express the specific marker of mature oligodendrocyte MBP (D), while none or rare cells express the specific astrocyte [GFAP, (E)] or neuronal [MAP2, (F)] markers. Data are presented as mean \pm SEM; ${ }^{* * *} p<0.0001 ;{ }^{* * *} p<0.001 ;{ }^{* *} p<0.01 ;{ }^{*} p<0.05 ;$ n.d., not detectable. Images are single plane confocal images. Cell nuclei are visualized by TO-PRO3 nuclear staining (blue). Scale bars: $25 \mu \mathrm{m}$.

(Fumagalli et al., 2015) (Figure 2B, red bars). Meningeal-derived oligodendrocyte lineage cells (Step Go3) and NG2-derived oligodendrocytes expressed comparable levels of Cnp, Mog, Mag, and $P l p 1$ specific oligodendrocyte genes (Figure 2B).

Altogether, these results indicate that the protocol allows a gradual in vitro differentiation of meningeal-derived NSCs toward the mature oligodendroglial lineage. Indeed, meningealderived NSCs progressively increase the specific oligodendrocyterelated gene expression levels while downregulating immature NSC genes.

\section{Meningeal-Derived NSCs Differentiated Homogeneously into Oligodendrocyte Lineage Cells}

Cell transplantation, as well as drug screening assay, requires high numbers of pure, homogeneously differentiated mature cells. We therefore tested whether our protocol induced differentiation of meningeal-derived NSCs specifically into mature oligodendrocytes, with no contamination of other cell types. To assess the purity of the differentiated meningeal-derived oligodendrocyte lineage cell population, we analyzed the gene expression of neuronal and glial genes during all phases of the differentiation protocol. We could not detect expression of the neuronal-specific gene Mtap2 (Izant and McIntosh, 1980) and of the astrocyte-specific genes Gfap (Eng, 1985) and Aqp4 (Yoneda et al., 2001) (Figure 2C) in each phase of the protocol analyzed. In line with previous reports (Cahoy et al., 2008), we detected low levels of expression of the neural precursor marker $D c x$ (Brown et al., 2003) the immature neuronal marker class III $\beta$-tubulin (Tub3) and the synaptic protein synaptotagmin 1 (Syt1) (Figure 2C). In accordance to previous findings (Cahoy et al., 2008), although low in absolute values, Tub3 and Syt1 increased approximately two-fold in the last oligodendrocyte differentiation phase (Step Go3) (Figure 2C). As confirmation, immunofluorescence analysis revealed that by the end of the 
protocol, the majority of the cells expressed the oligodendrocyte specific protein MBP (Figures 2D, 3A,E), while none or rare cells were positive for the astrocyte marker GFAP (Eng, 1985) and the neuronal marker MAP2 (Izant and McIntosh, 1980) (Figures 2E,F).

These data indicate that the meningeal-derived oligodendrocyte lineage cell culture does not include cells belonging to astrocyte or neuronal lineages, suggesting that they homogenously differentiated into oligodendrocytes.

\section{Evaluation of Meningeal-Derived Oligodendrocyte Lineage Cell Maturation}

To further assess the degree of maturation of the meningealderived oligodendrocyte lineage cells at each phase of the protocol, we assessed and quantified by immunofluorescence analysis the number of differentiating cells expressing the NSC marker nestin (Lendahl et al., 1990) (Figures 3A,B), the oligodendrocyte precursor marker NG2 (Figures $3 \mathbf{A}, \mathbf{C}$ ), the immature/intermediate oligodendrocyte progenitor marker $\mathrm{O} 4$ (Gard and Pfeiffer, 1989) (Figures 3A,D) the myelin component MBP (Campagnoni and Macklin, 1988) and GalC (Ranscht et al., 1982) (Figures 3A,E,F). We found that the majority of the neurospheres (NS) expressed, as expected, the NSC marker nestin (Figures 3A,B). Following oligodendrocyte precursor induction (Step Go1), nestin expression was decreased, while the early oligodendrocyte precursor marker (NG2) was statistically increased (Figures 3A-C). At this stage, the intermediate and mature oligodendrocyte markers were expressed at low levels (Figures 3C-F). In Step Go2, the immature oligodendrocyte marker $\mathrm{O} 4$ was statistically increased, while nestin and the early oligodendrocyte marker NG2 expression was decreased, suggesting that meningealderived NSCs were progressively differentiating into immature oligodendrocyte lineage cells (Figures 3A-D). The myelin components GalC and MBP, typically expressed by mature oligodendrocytes (Campagnoni and Macklin, 1988) were slightly increased in Step Go2 and were statistically significantly increased in Step Go3, indicating that meningeal-derived oligodendrocyte lineage cells have reached the maximum stage of the maturation process by the end of the differentiation protocol (Figures 3A,E,F).

Mature oligodendrocytes extend numerous processes; thus, to evaluate the degree of differentiation of the meningeal-derived oligodendrocyte lineage cells we quantified the number of cell branchings (Pfeiffer et al., 1993). To quantify the branchings, we immunostained for $\mathrm{MBP}$ and GalC the differentiating oligodendrocyte and we counted the branchings extending from each single cell through every step of the protocol (Figures 3G-I). We found that the number of branchings for each cell progressively statistically increased by reaching a mean of about 20 branchings/cell, typical of mature oligodendrocytes (Butt et al., 1994) in the last phase of the protocol (Figures 3G-I).

Altogether, those data suggest the meningeal-derived neurospheres are induced to differentiate progressively to oligodendrocyte precursors, immature oligodendrocytes and mature oligodendrocyte lineage cells.

\section{In Vivo-Remyelinating Potential of Meningeal-Derived Oligodendrocytes}

To assess the in vivo remyelinating potential of the meningealderived oligodendrocyte lineage cells, we developed a controlled model of in vivo focal spinal cord chemical demyelination by injecting the demyelinating drug LPC in the dorsal columns of the spinal cord. After 7 days from the injection of LPC (7 DPI), a focal demyelinated area was clearly evident at the dorsal column region of the spinal cord parenchyma. We transplanted eGFP ${ }^{+}$ meningeal-derived oligodendrocytes into the demyelinated area at 7 DPI and we analyzed their myelinating potential 21 days after the transplantation (21 DPT) [see Materials and Methods section Quantitative Real-time RT (Reverse Transcription)-PCR Analysis (qRT-PCR)]. LFB staining of the spinal cords of healthy control (not injured), LPC-control (injected with vehicle) and LPC-transplanted animal group at 21 DPT showed the difference in the myelin content among the groups (Figures $4 \mathrm{~A}-\mathrm{C}$ ). Importantly, myelin quantification in the dorsal column region of the spinal cords showed a statistical significant increase of the percentage of myelin in the spinal cords of LPC-transplanted group compared to the LPC-control group (Figure 4D).

To confirm the presence of transplanted $\mathrm{eGFP}^{+}$meningealderived oligodendrocyte lineage cells in LPC-transplanted rats, we analyzed their location and fate. As expected, at 1 DPT immunofluorescence analysis revealed that $\mathrm{eGFP}^{+}$meningealderived oligodendrocyte lineage cells were localized in the spinal cord parenchyma (Figures 4E,F) of all LPC-transplanted animals. Healthy and LPC-control rats did not exhibit such labeling. At $21 \mathrm{DPT}^{\mathrm{eGFP}}{ }^{+}$cells persist in the $\mathrm{LPC}$-lesion region and expressed MBP (Figures 4G-I). The immunostaining for neurofilament (NF160) suggested that $\mathrm{eGFP}^{+}$transplanted cells were in close contact with axons that maintained their integrity after the treatment with LPC (Figures 4J-L).

\section{DISCUSSION}

In this study, we described an efficient method to obtain high yield of oligodendrocyte lineage cells from a small rat meningeal biopsy. Our aim was to develop a protocol potentially applicable for cell therapy and for in vitro drug screening.

Although significant progresses have been made in developing pharmacological therapies to increase oligodendrocyte lineage cell number and optimize their differentiation, there is still an unmet need for translating successful remyelination in clinical setting. In vitro oligodendrocyte cultures can be useful for both cell therapy and drug screening purposes. Currently, in vitro expansion of oligodendrocyte lineage cells can be obtained by (i) sorting of oligodendrocyte precursors from postnatal or adult brain tissue (Zhu et al., 2007; Pedraza et al., 2008, 2014; Fumagalli et al., 2011, 2015; Dugas and Emery, 2013a,b; Emery and Dugas, 2013; Medina-Rodríguez et al., 2013; Lu et al., 2015); (ii) culturing and differentiating ESCs into oligodendrocytes (Glaser et al., 2004; Zhang et al., 2004; Chojnacki and Weiss, 2008; Jiang et al., 2010; Neri et al., 2010; Sundberg et al., 2010; Sharp et al., 2011; Neman and de Vellis, 2012; Alsanie et al., 2013; Franco et al., 2015; Kerman et al., 2015; Wang 

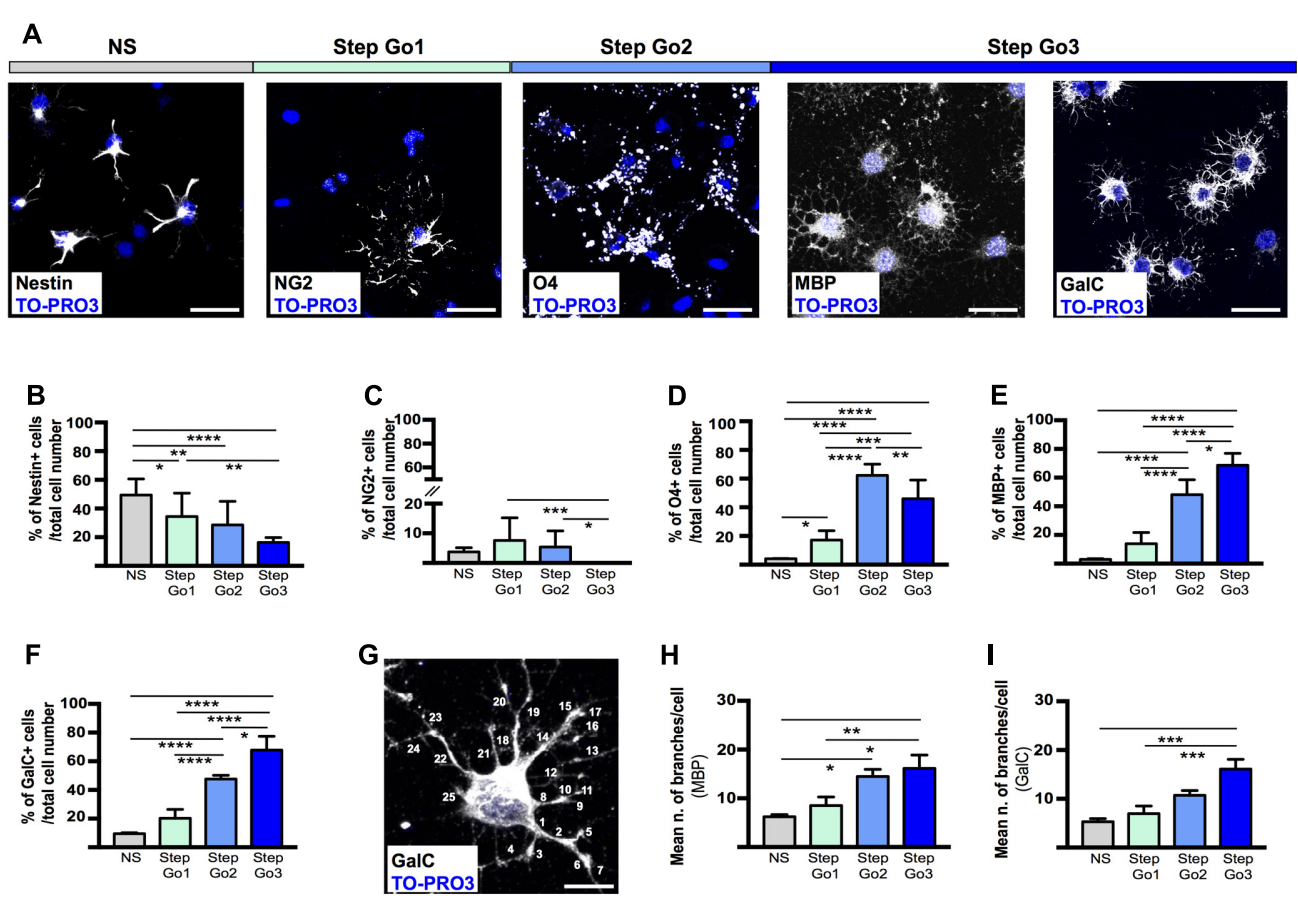

FIGURE 3 | Stage-specific oligodendrocyte differentiating marker expression. (A) Representative immunostaining images of meningeal-derived differentiating oligodendrocytes (white) at each stage of the differentiation protocol. In NS stage, meningeal-derived cells express the specific marker of stemness, nestin; in Step Go1, meningeal-derived cells express the specific marker of oligodendrocyte precursors, NG2; in Step Go2, meningeal-derived cells express the specific marker of immature oligodendrocytes, O4 and finally in Step Go3 meningeal-derived cells express specific markers of mature oligodendrocytes, MBP and GalC. (B-F) Graphs representing the percentage number of nestin ${ }^{+} \mathbf{( B )}, \mathrm{NG}^{+} \mathbf{( C )}, \mathrm{O}^{+} \mathbf{( D )}, \mathrm{MBP}^{+}(\mathbf{E})$, and $\mathrm{GalC}^{+}(\mathbf{F})$ cells among the total counted cells at each stage of the oligodendrocyte differentiation protocol. In (B), nestin+ cells significantly decrease along the oligodendrocyte differentiation protocol (NS vs. Step Go1, NS vs. Step Go2, NS vs. Step Go3). In (C), NG2+ cells, increase from NS to Step Go1 and decrease in the following steps. In (D), O4+ cells peak at Step Go2 (Step Go2 vs. NS and Step Go2 vs. Step Go1). In (E,F), MBP $^{+}$and GalC ${ }^{+}$cells significantly increase in Step Go3. (G-I) Representative immunostaining image (G) and quantification

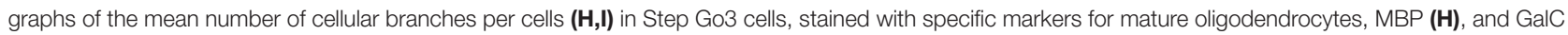
(G,I). These data show that the number of branches significantly increases along the oligodendrocyte differentiation protocol and highlight the maturation of meningeal-derived oligodendrocytes obtained at Step Go3 (MBP: Step Go2 vs. NS, Step Go3 vs. NS, Step Go3 vs. Step Go1; GalC: Step Go3 vs. NS, Step Go3 vs. Step Go1). Quantitative data are mean \pm SEM; ${ }^{* * *} p<0.0001 ;{ }^{* * *} p<0.001 ;{ }^{* *} p<0.01 ;{ }^{*} p<0.05$. All the images single plane confocal images. Cell nuclei are visualized by TO-PRO3 nuclear staining (blue). Scale bars: $25 \mu \mathrm{m}$.

et al., 2015; Yamashita et al., 2017; Yao et al., 2017) and (iii) generating and differentiating oligodendrocytes from patientderived iPSCs (Khazaei et al., 2007; Hu et al., 2009; Czepiel et al., 2011; Ogawa et al., 2011; Sundberg et al., 2011; Douvaras and Fossati, 2015; Gorris et al., 2015; Li et al., 2016; Kim et al., 2017; Rodrigues et al., 2017). All these available methods present some pitfalls that limit their clinical exploitation. In vitro culture of sorted oligodendrocyte precursors requires sampling of sizable brain tissue and does not always provide a pure oligodendrocyte expansion. ESCs have remarkable long-term proliferative potential, providing the possibility of unlimited expansion in culture and a broad differentiation potential. However, there are important ethical and safety issues, including the need of immunosuppressant therapy that increases the risk of teratoma formation. The production of oligodendrocyte-like cells directly from induced patient somatic cells is the most promising technique for autologous transplantation purposes. The risk of tumorigenicity, however, dampens its clinical applicability (Ben-David and Benvenisty, 2011). Transplantation of high numbers of autologous mature oligodendrocytes from living adult subject would represent the gold standard approach for cell therapy.

We identified in meninges the presence of NSCs, endowed of neural differentiation potential both in vitro and in vivo (Bifari et al., 2009, 2015, 2017; Decimo et al., 2011, 2012a,b). Meninges are a more accessible tissue compared to brain and spinal cord parenchyma. Moreover, NSCs are retained in adult brain and spinal cord meninges, thus there is no need of artificial in vitro transformation. We therefore developed a protocol to obtain oligodendrocyte lineage cells derived from adult rat meningeal biopsy. We optimized the protocol to address the most relevant issues for clinical translation including (i) short time of in vitro cell expansion, (ii) welldefined media conditions, and (iii) homogeneous phenotype of differentiated cells. We obtained a high number of meningealderived oligodendrocyte lineage cells (10 million cells) in a relatively short period of time (approximately 4 weeks). In addition, in vitro meningeal-derived oligodendrocyte lineage cell expansion and differentiation were carried out in welldefined culture media (in the absence of serum) and adhesion 

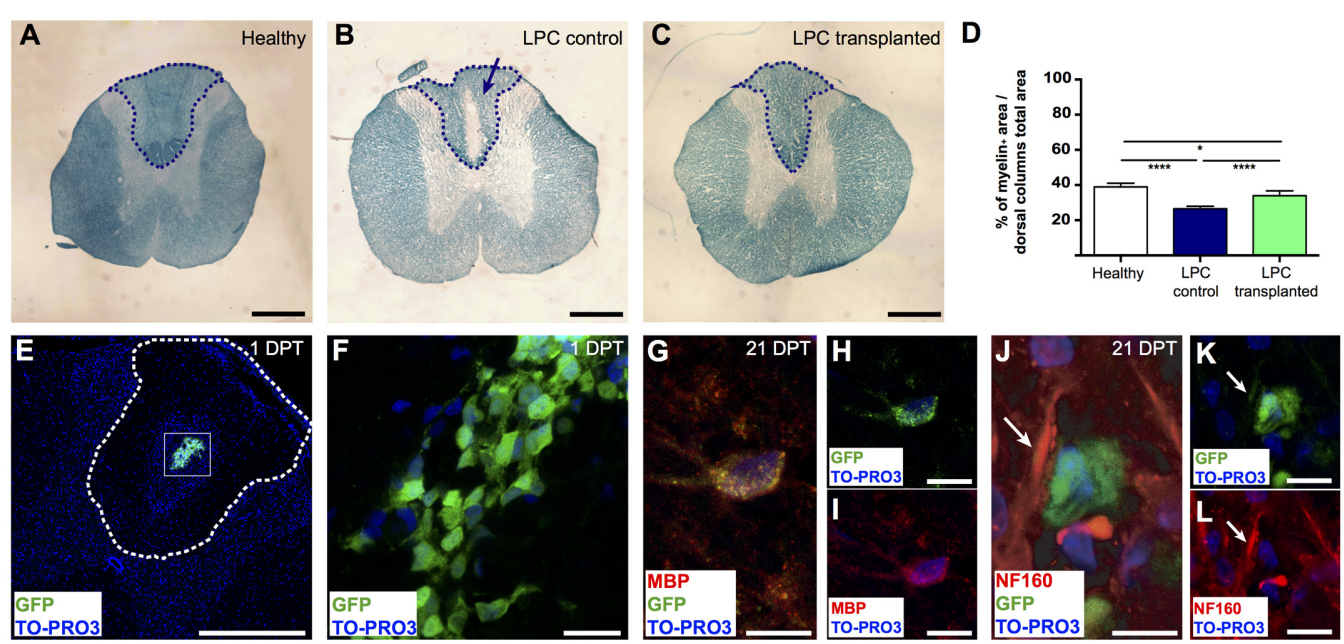

FIGURE 4 | Remyelinating potential of transplanted meningeal-derived oligodendrocytes. (A-C) Brightfield images of spinal cord transversal sections of healthy, LPC-control, and LPC-transplanted rats stained with specific myelin staining LFB. LFB allows the identification of the myelin content of the tissue (blue) from the demyelinated area (white). While spinal cord sections of healthy rat did not show any evidence of demyelination (A), spinal cord sections of LPC-control rats showed a focal demyelination in the injection sites, as indicated by the blue arrow (B). (C) Spinal cord sections of LPC-transplanted rats showed an higher intensity of the LFB staining around the injection site compared to LPC-control rat sections. (D) The graph represents the percentage of the myelin content in the dorsal column of the spinal cord sections of healthy $(38.94 \% \pm 1.2 \%)$, LPC-control $(26.42 \% \pm 0.6 \%)$, and LPC-transplanted $(33.97 \% \pm 1.1 \%)$ rats, calculated as myelin positive pixels in the dorsal column among the pixels of the total area of the dorsal column. The blue dashed lines in (A-C) indicate the dorsal column areas of the spinal cord sections of healthy, LPC-control, and LPC-transplanted rats, that represent the LPC-lesioned area considered for the myelin content quantification. The analysis shows that transplantation of meningeal-derived oligodendrocytes resulted in a significantly increased myelin content percentage in LPC-transplanted sections compared to LPC-controls sections. Quantitative data are expressed as means \pm SEM; $n=3$ in healthy animals, $n=6$ in LPC animals; ${ }^{*} p \leq 0.05$, ${ }^{* * * *} p \leq 0.0001$. The average value was calculated for healthy control, LPC-control and LPC-transplanted rats ( $n \geq 20$ slices/animal). (E,F) Immunostaining for GFP (green) and TO-PRO3 nuclei (blue) in a spinal cord section of a LPC-transplanted rat at 1 DPT, showing that eGFP ${ }^{+}$meningeal-derived oligodendrocytes were localized inside the spinal cord parenchyma close to the LPC lesion site. The white dashed line in (E) indicates the dorsal columns of the spinal cord, (F) is a higher magnification of the box in (E). (G-I) Immunostaining of a spinal cord section of a LPC-transplanted rat at 21 DPT, showing that eGFP+ meningeal-derived oligodendrocytes (green) co-express the specific marker for mature oligodendrocytes, MBP (red). Merged image in (G); GFP (green) and TO-PRO3 (blue) in (H); MBP (red) and TO-PRO3 (blue) in (I). (J-L) Immunostaining of a spinal cord section of a LPC-transplanted rat at 21 DPT, showing that eGFP+ meningeal-derived oligodendrocytes (green) are in close contact to the neuron neurofilament, stained with NF160 (white arrows in (J-L). Merged image in (J); GFP (green) and TO-PRO3 (blue) in (K); NF160 (red) and TO-PRO3 (blue) in (L). (E) and (F) are maximum Z-projection images of confocal images. Scale bars: $1 \mathrm{~mm}(\mathbf{A}-\mathbf{C}), 500 \mu \mathrm{m}(\mathbf{E}), 20 \mu \mathrm{m}(\mathbf{F}, \mathbf{H}, \mathbf{I}, \mathbf{K}, \mathbf{L}), 40 \mu \mathrm{m}(\mathbf{G}, \mathbf{J})$.

substrate (poly-D-lysine), therefore enhancing standardization and the potential clinical translation of the protocol. We cultured the whole rat meningeal biopsy avoiding intermediate steps of enzymatic and/or mechanical dissociation, in order to minimize in vitro manipulation and maximizing cellular viability. Meningeal-derived NSCs were differentiated into a homogeneous culture of mature oligodendrocyte lineage cells as suggested by the expression of oligodendrocyte markers (GalC and MBP) and the lack of expression of neuronal and astrocyte markers (Map2 and GFAP) (Figures 2E,F) (Campagnoni and Macklin, 1988; Butt et al., 1994). Indeed, meningeal-derived oligodendrocyte lineage cells express comparable levels of oligodendrocyte specific genes to those of mature NG2-derived oligodendrocytes (Figure 2B) (Cahoy et al., 2008).

Notably, meningeal-derived oligodendrocyte lineage cells showed in vivo remyelinating potential (Liu et al., 2000; Razavi et al., 2017). To assess the in vivo differentiation and remyelinating potential of the meningeal-derived oligodendrocyte lineage cells, we used the animal model of focal spinal cord chemical demyelination, by injecting the drug LPC. Our results indicate that meningeal-derived oligodendrocyte lineage cells are endowed of in vivo differentiation and remyelinating potential. Although LPC-induced demyelination is a valuable tool for screening candidates for remyelinationpromoting therapies, this model did not include all the complex interactions (i.e., vascular and autoimmune) occurring in the most common demyelinating diseases such as stroke and MS. In this work, we aimed to first assess the in vivo remyelinating potential rather than the overall therapeutic effect of the meningeal-derived oligodendrocyte linage cells. We therefore choose the animal model of chemical LPC demyelination. Previous works suggest that meningeal resident NSCs react to brain and spinal cord damage (Decimo et al., 2011; Nakagomi et al., 2011, 2012; Ninomiya et al., 2013) by increasing their stemness and differentiation potential. However, whether meningeal resident NSCs react similarly following complex demyelinating diseases remains to be determined.

The development of a successful protocol for OPC/oligodendrocyte lineage cell culture of adult origin could provide a useful tool for the in vitro screening and testing of drugs able to influence the biology and remyelinating potential of OPCs (Allen et al., 2005; Soldatow et al., 2013; Kerman et al., 2015). Different strategies are now under investigation for in vitro drug screening, as the use of primary cultures, including OPCs 
(Merrill, 2008; Gonzalez et al., 2016; Lariosa-Willingham et al., 2016), iPSCs (Iwata et al., 2017; Rana et al., 2017), organoids (Vrij et al., 2016; Pino et al., 2017), spheroids (Sarkar et al., 2017; Sirenko et al., 2017), and bioprinted 3D tissues (Chang et al., 2010; Massa et al., 2017). However, none of these methods is able to provide adult patient-specific oligodendrocytes without major in vitro transformation. On the contrary, meningealderived oligodendrocyte lineage cells may be potentially used for precision medicine to develop a patient-specific assay to test drugs, starting from a population of meningeal cells extracted directly from the living patient.

Overall, our protocol has potential of translation and application in autologous setting. Since, we harvested meninges covering the spinal cord, we avoided dangerous invasive sampling of the delicate CNS tissue. Moreover, we developed a protocol to produce a sufficient number ( $>10$ millions) of transplantable cells starting from a single donor tissue extraction. Therefore, this method may be applicable in autologous settings, as a small meningeal biopsy could potentially be harvested from a subject and directly cultured in vitro to obtain high yield of transplantable meningeal-derived oligodendrocyte lineage cells. Subsequently, in vitro expanded and differentiated meningeal-derived oligodendrocyte lineage cells could be transplanted in the same donor from which the meninges were sampled. This protocol may be exploited in the future to obtain oligodendrocytes for cell therapy of different demyelinating disease models, including MS, stroke and traumatic brain and spinal cord injuries, thus further testing the therapeutic potential of meningeal-derived oligodendrocyte lineage cells.

\section{CONCLUSION}

The physiological function of adult meningeal-resident NSCs, as well as their complete cellular and molecular characterization, is only partially known. The presence of meningeal-resident progenitor cells has, however, been reported both in adult rodent and humans (DeGiorgio et al., 1994; Bifari et al., 2009, 2015, 2017; Decimo et al., 2011, 2012a,b; Petricevic et al., 2011). Meningeal-resident NSCs have been shown to react to CNS damage (Decimo et al., 2011; Nakagomi et al., 2011, 2012; Ninomiya et al., 2013). With this work, we identified meninges

\section{REFERENCES}

Allen, D. D., Caviedes, R., Cárdenas, A. M., Shimahara, T., Segura-Aguilar, J., and Caviedes, P. A. (2005). Cell lines as in vitro models for drug screening and toxicity studies. Drug Dev. Ind. Pharm. 31, 757-768. doi: 10.1080/ 03639040500216246

Almazan, G., Honegger, P. F., and Matthieu, J. M. (1985). Triiodothyronine stimulation of oligodendroglial differentiation and myelination. A developmental study. Dev. Neurosci. 7, 45-54. doi: 10.1159/0001 12275

Alsanie, W. F., Niclis, J. C., and Petratos, S. (2013). Human embryonic stem cell-derived oligodendrocytes: protocols and perspectives. Stem Cells Dev. 22, 2459-2476. doi: 10.1089/scd.2012.0520

Baumann, N., and Pham-Dinh, D. (2001). Biology of oligodendrocyte and myelin in the mammalian central nervous system. Physiol. Rev. 81, 871-927. as an optimal source of adult NSCs, that can be easily isolated, expanded, and differentiated into oligodendrocyte lineage cells. These cells express the phenotypic and genetic markers of bona fide oligodendrocytes, are functional and able to restore myelin content in a chemical demyelinating model. However, how these in vitro generated meningeal-derived oligodendrocyte lineage cells may survive and what is their regenerative potential in different demyelinating pathological microenvironment, such as MS, ischemic, and traumatic injuries, will need further investigations.

\section{AUTHOR CONTRIBUTIONS}

$\mathrm{SD}, \mathrm{AP}, \mathrm{VB}, \mathrm{FB}$, and ID designed the study, performed the experiments, and analyzed and interpreted data. FP, AB, SZ, CA, DM, GM, and MF assisted with molecular analyses, animal work, and histochemical analysis. PG and FJR set-up the LPC spinal cord lesion and transplanted the cells. GM performed gene expression analysis. MF and EB cultured and differentiated NG2-derived oligodendrocytes. SD, AP, VB, GF, FB, and ID wrote the paper. All authors discussed results and commented on the manuscript. FB and ID conceptualized the study, supervised the project, and have the scientific direction.

\section{FUNDING}

This work was supported by GALM (Gruppo Animazione Lesionati Midollari); La Colonna, Italy; and by International Foundation for Research in Paraplegie [grant number RP-P126]. ID is supported by University of Verona [grant number DDSPFUR-6616]; FB is supported by University of Milan [grant number BIOMETRA15-6-3003005-1].

\section{ACKNOWLEDGMENTS}

We thank Marzia Di Chio (University of Verona) for helpful suggestions and technical assistance. We thank Dr. Elisa Tedeschi (University of Verona) and the technical staff of C.I.R.S.A.L. for assistance with the animal care and Dr. Erika Lorenzetto (University of Verona) for technical assistance.

Ben-David, U., and Benvenisty, N. (2011). The tumorigenicity of human embryonic and induced pluripotent stem cells. Nat. Rev. Cancer 11, 268-277. doi: $10.1038 / \mathrm{nrc} 3034$

Bifari, F., Berton, V., Pino, A., Kusalo, M., Malpeli, G., Di Chio, M., et al. (2015). Meninges harbor cells expressing neural precursor markers during development and adulthood. Front. Cell. Neurosci. 9:383. doi: 10.3389/fncel. 2015.00383

Bifari, F., Decimo, I., Chiamulera, C., Bersan, E., Malpeli, G., Johansson, J., et al. (2009). Novel stem/progenitor cells with neuronal differentiation potential reside in the leptomeningeal niche. J. Cell Mol. Med. 13, 3195-3208. doi: 10.1111/j.1582-4934.2009.00706.x

Bifari, F., Decimo, I., Pino, A., Llorens-Bobadilla, E., Zhao, S., Lange, C., et al. (2017). Neurogenic radial glia-like cells in meninges migrate and differentiate into functionally integrated neurons in the neonatal cortex. Cell Stem Cell 20, 360.e7-373.e7. doi: 10.1016/j.stem.2016.10.020 
Brown, J. P., Couillard-Després, S., Cooper-Kuhn, C. M., Winkler, J., Aigner, L., and Kuhn, H. G. (2003). Transient expression of doublecortin during adult neurogenesis. J. Comp. Neurol. 467, 1-10. doi: 10.1002/cne.10874

Butt, A. M., Colquhoun, K., Tutton, M., and Berry, M. (1994). Three-dimensional morphology of astrocytes and oligodendrocytes in the intact mouse optic nerve. J. Neurocytol. 8, 469-485. doi: 10.1007/BF01184071

Cahoy, J. D., Emery, B., Kaushal, A., Foo, L. C., Zamanian, J. L., Christopherson, K. S., et al. (2008). A transcriptome database for astrocytes, neurons, and oligodendrocytes: a new resource for understanding brain development and function. J. Neurosci. 28, 264-278. doi: 10.1523/JNEUROSCI.4178-07.2008

Calver, A. R., Hall, A. C., Yu, W.-P., Walsh, F. S., Heath, J. K., Betsholtz, C., et al. (1998). Oligodendrocyte population dynamics and the role of PDGF in vivo. Neuron 20, 869-882. doi: 10.1016/S0896-6273(00)80469-9

Campagnoni, A. T., and Macklin, W. B. (1988). Cellular and molecular aspects of myelin protein gene expression. Mol. Neurobiol. 2, 41-89. doi: 10.1007/ BF02935632

Chang, R., Emami, K., Wu, H., and Sun, W. (2010). Biofabrication of a three-dimensional liver micro-organ as an in vitro drug metabolism model. Biofabrication 2:045004. doi: 10.1088/1758-5082/2/4/045004

Chen, L., Huang, H., Xi, H., Zhang, F., Liu, Y., Chen, D., et al. (2014). A prospective randomized double-blind clinical trial using a combination of olfactory ensheathing cells and Schwann cells for the treatment of chronic complete spinal cord injuries. Cell Transplant. 23(Suppl. 1), S35-S44. doi: 10.3727/096368914X685014

Chojnacki, A., and Weiss, S. (2008). Production of neurons, astrocytes and oligodendrocytes from mammalian CNS stem cells. Nat. Protoc. 3, 935-940. doi: $10.1038 /$ nprot.2008.55

Czepiel, M., Balasubramaniyan, V., Schaafsma, W., Stancic, M., Mikkers, H., Huisman, C., et al. (2011). Differentiation of induced pluripotent stem cells into functional oligodendrocytes. Glia 59, 882-892. doi: 10.1002/glia.21159

Decimo, I., Bifari, F., Krampera, M., and Fumagalli, G. (2012a). Neural stem cell niches in health and diseases. Curr. Pharm. Des. 18, 1755-1783.

Decimo, I., Bifari, F., Rodriguez, F. J., Malpeli, G., Dolci, S., Lavarini, V., et al. (2011). Nestin- and doublecortin-positive cells reside in adult spinal cord meninges and participate in injury-induced parenchymal reaction. Stem Cells 29, 2062-2076. doi: 10.1002/stem.766

Decimo, I., Fumagalli, G., Berton, V., Krampera, M., and Bifari, F. (2012b). Meninges: from protective membrane to stem cell niche. Am. J. Stem Cells 1, 92-105.

DeGiorgio, L. A., Sheu, K.-F. R., and Blass, J. P. (1994). Culture from human leptomeninges of cells containing neurofilament protein and neuronspecific enolase. J. Neurol. Sci. 124, 141-148. doi: 10.1016/0022-510X(94) 90319-0

Douvaras, P., and Fossati, V. (2015). Generation and isolation of oligodendrocyte progenitor cells from human pluripotent stem cells. Nat. Protoc. 10, 1143-1154. doi: $10.1038 /$ nprot.2015.075

Dugas, J. C., and Emery, B. (2013a). Purification and culture of oligodendrocyte lineage cells. Cold Spring Harb. Protoc. 2013, 810-814. doi: 10.1101/pdb. top074898

Dugas, J. C., and Emery, B. (2013b). Purification of oligodendrocyte precursor cells from rat cortices by immunopanning. Cold Spring Harb. Protoc. 2013, 745-758. doi: $10.1101 /$ pdb.prot070862

Dugas, J. C., Tai, Y. C., Speed, T. P., Ngai, J., and Barres, B. A. (2006). Functional genomic analysis of oligodendrocyte differentiation. J. Neurosci. 26, 10967-10983. doi: 10.1523/JNEUROSCI.2572-06.2006

Duncan, I. D., and Radcliff, A. B. (2016). Inherited and acquired disorders of myelin: the underlying myelin pathology. Exp. Neurol. 283(Pt B), 452-475. doi: 10.1016/j.expneurol.2016.04.002

Emery, B., and Dugas, J. C. (2013). Purification of oligodendrocyte lineage cells from mouse cortices by immunopanning. Cold Spring Harb. Protoc. 2013, 854-868. doi: 10.1101/pdb.prot073973

Eng, L. F. (1985). Glial fibrillary acidic protein (GFAP): the major protein of glial intermediate filaments in differentiated astrocytes. J. Neuroimmunol. 8, 203-214. doi: 10.1016/S0165-5728(85)80063-1

Engel, U., and Wolswijk, G. (1996). Oligodendrocyte-type-2 astrocyte (O-2A) progenitor cells derived from adult rat spinal cord: in vitro characteristics and response to PDGF, bFGF and NT-3. Glia 1, 16-26. doi: 10.1002/(SICI)10981136(199601) 16:1<16::AID-GLIA3>3.0.CO;2-9
Fouad, K., Schnell, L., Bunge, M. B., Schwab, M. E., Liebscher, T., and Pearse, D. D. (2005). Combining Schwann cell bridges and olfactory-ensheathing glia grafts with chondroitinase promotes locomotor recovery after complete transection of the spinal cord. J. Neurosci. 25, 1169-1178. doi: 10.1523/JNEUROSCI.356204.2005

Franco, P. G., Pasquini, J. M., and Silvestroff, L. (2015). Optimizing culture medium composition to improve oligodendrocyte progenitor cell yields in vitro from subventricular zone-derived neural progenitor cell neurospheres. PLOS ONE 10:e121774. doi: 10.1371/journal.pone.0121774

Franklin, R. J., and Ffrench-Constant, C. (2008). Remyelination in the CNS: from biology to therapy. Nat. Rev. Neurosci. 9, 839-855. doi: 10.1038/nrn2480

Franklin, R. J. M. (2015). Regenerative medicines for remyelination: from aspiration to reality. Cell Stem Cell 16, 576-577. doi: 10.1016/j.stem.2015.05.010

Fumagalli, M., Bonfanti, E., Daniele, S., Zappelli, E., Lecca, D., Martini, C., et al. (2015). The ubiquitin ligase $\mathrm{Mdm} 2$ controls oligodendrocyte maturation by intertwining mTOR with $\mathrm{G}$ protein-coupled receptor kinase 2 in the regulation of GPR17 receptor desensitization. Glia 63, 2327-2339. doi: 10.1002/glia.22896

Fumagalli, M., Daniele, S., Lecca, D., Lee, P. R., Parravicini, C., Fields, R. D., et al. (2011). Phenotypic changes, signaling pathway, and functional correlates of GPR17-expressing neural precursor cells during oligodendrocyte differentiation. J. Biol. Chem. 286, 10593-10604. doi: 10.1074/jbc.M110.162867

Gallo, V., and Deneen, B. (2014). Glial development: the crossroads of regeneration and repair in the CNS. Neuron 83, 283-308. doi: 10.1016/j.neuron.2014.06.010

Gard, A. L., and Pfeiffer, S. E. (1989). Oligodendrocyte progenitors isolated directly from developing telencephalon at a specific phenotypic stage: myelinogenic potential in a defined environment. Development 106, 119-132.

Glaser, T., Perez-Bouza, A., Klein, K., and Brüstle, O. (2004). Generation of purified oligodendrocyte progenitors from embryonic stem cells. FASEB J. 112-114. doi: 10.1096/fj.04-1931fje

Goldman, S. A. (2016). Stem and progenitor cell-based therapy of the central nervous system: hopes, hype, and wishful thinking. Cell Stem Cell 18, 174-188. doi: 10.1016/j.stem.2016.01.012

Gonzalez, G. A., Hofer, M. P., Syed, Y. A., Amaral, A. I., Rundle, J., Rahman, S., et al. (2016). Tamoxifen accelerates the repair of demyelinated lesions in the central nervous system. Sci. Rep. 6:31599. doi: 10.1038/srep31599

Gorris, R., Fischer, J., Erwes, K. L., Kesavan, J., Peterson, D. A., Alexander, M., et al. (2015). Pluripotent stem cell-derived radial glia-like cells as stable intermediate for efficient generation of human oligodendrocytes. Glia 63, 2152-2167. doi: $10.1002 /$ glia.22882

Guest, J. D., Hiester, E. D., and Bunge, R. P. (2005). Demyelination and Schwann cell responses adjacent to injury epicenter cavities following chronic human spinal cord injury. Exp. Neurol. 192, 384-393. doi: 10.1016/j.expneurol.2004. 11.033

Hu, B.-Y., Du, Z.-W., and Zhang, S.-C. (2009). Differentiation of human oligodendrocytes from pluripotent stem cells. Nat. Protoc. 4, 1614-1622. doi: 10.1038/nprot.2009.186

Iwata, Y., Klaren, W. D., Lebakken, C. S., Grimm, F. A., and Rusyn, I. (2017). High-content assay multiplexing for vascular toxicity screening in induced pluripotent stem cell-derived endothelial cells and human umbilical vein endothelial cells. Assay Drug Dev. Technol. 15, 267-279. doi: 10.1089/adt. 2017.786

Izant, J. G., and McIntosh, J. R. (1980). Microtubule-associated proteins: a monoclonal antibody to MAP2 binds to differentiated neurons. Proc. Natl. Acad. Sci. U.S.A. 77, 4741-4745. doi: 10.1073/pnas.77.8.4741

Jiang, P., Selvaraj, V., and Deng, W. (2010). Differentiation of embryonic stem cells into oligodendrocyte precursors. J. Vis. Exp. 39:1960. doi: 10.3791/1960

Karoutzou, G., Emrich, H. M., and Dietrich, D. E. (2007). The myelin-pathogenesis puzzle in schizophrenia: a literature review. Mol. Psychiatry 13, 245-260. doi: 10.1038/sj.mp.4002096

Kerman, B. E., Kim, H. J., Padmanabhan, K., Mei, A., Georges, S., Joens, M. S., et al. (2015). In vitro myelin formation using embryonic stem cells. Development 142 , 2213-2225. doi: 10.1242/dev.116517

Khazaei, M., Ahuja, C. S., and Fehlings, M. G. (2007). Generation of oligodendrogenic spinal neural progenitor cells from human induced pluripotent stem cells. Curr. Protoc. Stem Cell Biol. 42, 2D.20.1-2D.20.14.

Kim, D.-S., Jung, S. J., Lee, J. S., Lim, B. Y., Kim, H. A., Yoo, J.-E., et al. (2017). Rapid generation of OPC-like cells from human pluripotent stem cells for treating spinal cord injury. Exp. Mol. Med. 49, e361. doi: 10.1038/emm.2017.106 
Lange, C., Turrero Garcia, M., Decimo, I., Bifari, F., Eelen, G., Quaegebeur, A., et al. (2016). Relief of hypoxia by angiogenesis promotes neural stem cell differentiation by targeting glycolysis. EMBO J. 35, 924-941. doi: 10.15252/ embj.201592372

Lariosa-Willingham, K. D., Rosler, E. S., Tung, J. S., Dugas, J. C., Collins, T. L., and Leonoudakis, D. (2016). A high throughput drug screening assay to identify compounds that promote oligodendrocyte differentiation using acutely dissociated and purified oligodendrocyte precursor cells. BMC Res. Notes 9:419. doi: 10.1186/s13104-016-2220-2

Lendahl, U., Zimmerman, L. B., and Mckay, R. D. (1990). CNS stem cells express a new class of intermediate filament protein. Cell 60, 585-595. doi: 10.1016/00928674(90)90662-X

Li, P., Li, M., Tang, X., Wang, S., Zhang, Y. A., and Chen, Z. (2016). Accelerated generation of oligodendrocyte progenitor cells from human induced pluripotent stem cells by forced expression of Sox10 and Olig2. Sci. China Life Sci. 59, 1131-1138. doi: 10.1007/s11427-016-0165-3

Liu, S., Qu, Y., Stewart, T. J., Howard, M. J., Chakrabortty, S., Holekamp, T. F., et al. (2000). Embryonic stem cells differentiate into oligodendrocytes and myelinate in culture and after spinal cord transplantation. Proc. Natl. Acad. Sci. U.S.A. 97, 6126-6131. doi: 10.1073/pnas.97.11.6126

Lu, Y., Yang, Y., Wang, Z., Wang, C., Du, Q., Wang, Q., et al. (2015). Isolation and culture of human oligodendrocyte precursor cells from neurospheres. Brain Res. Bull. 118, 17-24. doi: 10.1016/j.brainresbull.2015.08.008

Mackay-Sim, A., Féron, F., Cochrane, J., Bassingthwaighte, L., Bayliss, C., Davies, W., et al. (2008). Autologous olfactory ensheathing cell transplantation in human paraplegia: a 3-year clinical trial. Brain 131, 2376-2386. doi: 10.1093/ brain/awn 173

Martens, D. J., Tropepe, V., and Van Der Kooy, D. (2000). Separate proliferation kinetics of fibroblast growth factor-responsive and epidermal growth factorresponsive neural stem cells within the embryonic forebrain germinal zone. J. Neurosci. 20, 1085-1095.

Massa, S. A., Sakr, M. A., Seo, J., Bandaru, P., Arneri, A., Bersini, S., et al. (2017). Bioprinted 3D vascularized tissue model for drug toxicity analysis. Biomicrofluidics 11, 044109. doi: 10.1063/1.4994708

McKinnon, R. D., Matsui, T., Dubois-Dalcq, M., and Aaronsont, S. A. (1990). FGF modulates the PDGF-driven pathway of oligodendrocyte development. Neuron 5, 603-614. doi: 10.1016/0896-6273(90)90215-2

Medina-Rodríguez, E. M., Arenzana, F. J., Bribián, A., and De Castro, F. (2013). Protocol to isolate a large amount of functional oligodendrocyte precursor cells from the cerebral cortex of adult mice and humans. PLOS ONE 8:e81620. doi: 10.1371 /journal.pone.0081620

Merrill, J. E. (2008). In vitro and in vivo pharmacological models to assess demyelination and remyelination. Neuropsychopharmacology 34, 55-73. doi: $10.1038 /$ npp. 2008.145

Murrell, W., Wetzig, A., Donnellan, M., Féron, F., Burne, T., Meedeniya, A., et al. (2008). Olfactory mucosa is a potential source for autologous stem cell therapy for Parkinson's disease. Stem Cells 26, 2183-2192. doi: 10.1634/stemcells.20080074

Najm, F. J., Madhavan, M., Zaremba, A., Shick, E., Karl, R. T., Factor, D. C., et al. (2015). Drug-based modulation of endogenous stem cells promotes functional remyelination in vivo. Nature 522, 216-220. doi: 10.1038/nature14335

Nakagomi, T., Molnar, Z., Nakano-Doi, A., Taguchi, A., Saino, O., Kubo, S., et al. (2011). Ischemia-induced neural stem/progenitor cells in the pia mater following cortical infarction. Stem Cells Dev. 20, 2037-2051. doi: 10.1089/scd. 2011.0279

Nakagomi, T., Molnar, Z., Taguchi, A., Nakano-Doi, A., Lu, S., Kasahara, Y., et al. (2012). Leptomeningeal-derived doublecortin-expressing cells in poststroke brain. Stem Cells Dev. 21, 2350-2354. doi: 10.1089/scd.2011.0657

Neman, J., and de Vellis, J. (2012). A method for deriving homogenous population of oligodendrocytes from mouse embryonic stem cells. Dev. Neurobiol. 72, 777-788. doi: 10.1002/dneu.22008

Neri, M., Maderna, C., Ferrari, D., Cavazzin, C., Vescovi, A. L., and Gritti, A. (2010). Robust generation of oligodendrocyte progenitors from human neural stem cells and engraftment in experimental demyelination models in mice. PLOS ONE 5:e10145. doi: 10.1371/journal.pone.0010145

Ninomiya, S., Esumi, S., Ohta, K., Fukuda, T., Ito, T., Imayoshi, I., et al. (2013). Amygdala kindling induces nestin expression in the leptomeninges of the neocortex. Neurosci. Res. 75, 121-129. doi: 10.1016/j.neures.2012. 12.006

Nishiyama, A., Chang, A., and Trapp, B. D. (1999). NG ${ }^{2+}$ glial cells: a novel glial cell population in the adult brain. J. Neuropathol. Exp. Neurol. 11, 1113-1124. doi: 10.1097/00005072-199911000-00001

Nishiyama, A., Komitova, M., Suzuki, R., and Zhu, X. (2009). Polydendrocytes (NG2 cells): multifunctional cells with lineage plasticity. Nat. Rev. Neurosci. 10, 9-22. doi: 10.1038/nrn2495

Ogawa, S.-I., Tokumoto, Y., Miyake, J., and Nagamune, T. (2011). Induction of oligodendrocyte differentiation from adult human fibroblast-derived induced pluripotent stem cells. In Vitro Cell. Dev. Biol. Anim. 47, 464-469. doi: 10.1007/ s11626-011-9435-2

Pedraza, C. E., Monk, R., Lei, J., Hao, Q., and Macklin, W. B. (2008). Production, characterization, and efficient transfection of highly pure oligodendrocyte precursor cultures from mouse embryonic neural progenitors. Glia 56, 1339-1352. doi: 10.1002/glia.20702

Pedraza, C. E., Taylor, C., Pereira, A., Seng, M., Tham, C.-S., Izrael, M., et al. (2014). Induction of oligodendrocyte differentiation and in vitro myelination by inhibition of rho-associated kinase. ASN Neuro 6:1759091414538134. doi: $10.1177 / 1759091414538134$

Petricevic, J., Forempoher, G., Ostojic, L., Mardesic-Brakus, S., Andjelinovic, S., Vukojevic, K., et al. (2011). Expression of nestin, mesothelin and epithelial membrane antigen (EMA) in developing and adult human meninges and meningiomas. Acta Histochem. 113, 703-711. doi: 10.1016/j.acthis.2010.09.005

Pfeiffer, S. E., Warrington, A. E., and Bansal, R. (1993). The oligodendrocyte and its many cellular processes. Trends Cell Biol. 3, 191-197. doi: 10.1016/09628924(93)90213-K

Picard-Riera, N., Decker, L., Delarasse, C., Goude, K., Nait-Oumesmar, B., Liblau, R., et al. (2002). Experimental autoimmune encephalomyelitis mobilizes neural progenitors from the subventricular zone to undergo oligodendrogenesis in adult mice. Proc. Natl. Acad. Sci. U.S.A. 99, 13211-13216. doi: 10.1073/pnas. 192314199

Pino, A., Fumagalli, G., Bifari, F., and Decimo, I. (2017). New neurons in adult brain: distribution, molecular mechanisms and therapies. Biochem. Pharmacol. 141, 4-22. doi: 10.1016/j.bcp.2017.07.003

Powers, B. E., Sellers, D. L., Lovelett, E. A., Cheung, W., Aalami, S. P., Zapertov, N., et al. (2013). Remyelination reporter reveals prolonged refinement of spontaneously regenerated myelin. Proc. Natl. Acad. Sci. U.S.A. 110, 4075-4080. doi: 10.1073/pnas.1210293110

Rana, P., Luerman, G., Hess, D., Rubitski, E., Adkins, K., and Somps, C. (2017). Utilization of iPSC-derived human neurons for high-throughput druginduced peripheral neuropathy screening. Toxicol. In Vitro 45(Pt 1), 111-118. doi: 10.1016/j.tiv.2017.08.014

Ranscht, B., Clapshaw, P. A., Price, J., Noble, M., and Seifert, W. (1982). Development of oligodendrocytes and Schwann cells studied with a monoclonal antibody against galactocerebroside. Proc. Natl. Acad. Sci. U.S.A. 79, 2709-2713. doi: 10.1073/pnas.79.8.2709

Razavi, S., Ghasemi, N., Mardani, M., and Salehi, H. (2017). Remyelination improvement after neurotrophic factors secreting cells transplantation in rat spinal cord injury. Iran. J. Basic Med. Sci. 20, 392-398. doi: 10.22038/IJBMS. 2017.8580

Rivers, L. E., Young, K. M., Rizzi, M., Jamen, F., Psachoulia, K., Wade, A., et al. (2008). PDGFRA/NG2 glia generate myelinating oligodendrocytes and piriform projection neurons in adult mice. Nat. Neurosci. 11, 1392-1401. doi: 10.1038/nn.2220

Rodrigues, G. M. C., Gaj, T., Adil, M. M., Wahba, J., Rao, A. T., Lorbeer, F. K., et al. (2017). Defined and scalable differentiation of human oligodendrocyte precursors from pluripotent stem cells in a 3D culture system. Stem Cell Rep. 8, 1770-1783. doi: 10.1016/j.stemcr.2017.04.027

Sarkar, J., Kumari, J., Tonello, J. M., Kamihira, M., and Kumar, A. (2017). Enhanced hepatic functions of genetically modified mouse hepatoma cells by spheroid culture for drug toxicity screening. Biotechnol. J. doi: 10.1002/biot.201700274 [Epub ahead of print].

Schmahmann, J. D., Smith, E. E., Eichler, F. S., and Filley, C. M. (2008). Cerebral white matter. Ann. N. Y. Acad. Sci. 1142, 266-309. doi: 10.1196/annals.1444.017

Sharp, J., Hatch, M., Nistor, G., and Keirstead, H. (2011). "Derivation of oligodendrocyte progenitor cells from human embryonic stem cells," in Human 
Pluripotent Stem Cells: Methods and Protocols, eds P. H. Schwartz and R. L. Wesselschmidt (Totowa, NJ: Humana Press), 399-409.

Shi, H., Hu, X., Leak, R. K., Shi, Y., An, C., Suenaga, J., et al. (2015). Demyelination as a rational therapeutic target for ischemic or traumatic brain injury. Exp. Neurol. 272, 17-25. doi: 10.1016/j.expneurol.2015.03.017

Sirenko, O., Hancock, M. K., Crittenden, C., Hammer, M., Keating, S., Carlson, C. B., et al. (2017). Phenotypic assays for characterizing compound effects on induced pluripotent stem cell-derived cardiac spheroids. Assay Drug Dev. Technol. 15, 280-296. doi: 10.1089/adt.2017.792

Soldatow, V. Y., Lecluyse, E. L., Griffith, L. G., and Rusyn, I. (2013). In vitro models for liver toxicity testing. Toxicol. Res. 2, 23-39. doi: 10.1039/C2TX20051A

Solly, S. K., Thomas, J. L., Monge, M., Demerens, C., Lubetzki, C., Gardinier, M. V., et al. (1996). Myelin/oligodendrocyte glycoprotein (MOG) expression is associated with myelin deposition. Glia 18, 39-48. doi: 10.1002/(SICI)10981136(199609) 18:1<39::AID-GLIA4>3.0.CO;2-Z

Steinbeck, J. A., and Studer, L. (2015). Moving stem cells to the clinic: potential and limitations for brain repair. Neuron 86, 187-206. doi: 10.1016/j.neuron.2015.03.002

Sundberg, M., Hyysalo, A., Skottman, H., Shin, S., Vemuri, M., Suuronen, R., et al. (2011). A xeno-free culturing protocol for pluripotent stem cellderived oligodendrocyte precursor cell production. Regen. Med. 6, 449-460. doi: $10.2217 /$ rme.11.36

Sundberg, M., Skottman, H., Suuronen, R., and Narkilahti, S. (2010). Production and isolation of $\mathrm{NG}^{+}$oligodendrocyte precursors from human embryonic stem cells in defined serum-free medium. Stem Cell Res. 5, 91-103. doi: 10.1016/ j.scr.2010.04.005

Traka, M., Podojil, J. R., Mccarthy, D. P., Miller, S. D., and Popko, B. (2016). Oligodendrocyte death results in immune-mediated CNS demyelination. Nat. Neurosci. 19, 65-74. doi: 10.1038/nn.4193

Trounson, A., and McDonald, C. (2015). Stem cell therapies in clinical trials: progress and challenges. Cell Stem Cell 17, 11-22. doi: 10.1016/j.stem.2015.06.007

Vrij, E. J., Espinoza, S., Heilig, M., Kolew, A., Schneider, M., Van Blitterswijk, C. A., et al. (2016). 3D high throughput screening and profiling of embryoid bodies in thermoformed microwell plates. Lab Chip 16, 734-742. doi: 10.1039/c5lc01499a

Wang, C., Luan, Z., Yang, Y., Wang, Z., Wang, Q., Lu, Y., et al. (2015). High purity of human oligodendrocyte progenitor cells obtained from neural stem cells: suitable for clinical application. J. Neurosci. Methods 240, 61-66. doi: 10.1016/j.jneumeth.2014.10.017
Weiss, S., Dunne, C., Hewson, J., Wohl, C., Wheatley, M., Peterson, A. C., et al. (1996). Multipotent CNS stem cells are present in the adult mammalian spinal cord and ventricular neuroaxis. J. Neurosci. 16, 7599-7609.

Xin, M., Yue, T., Ma, Z., Wu, F.-F., Gow, A., and Lu, Q. R. (2005). Myelinogenesis and axonal recognition by oligodendrocytes in brain are uncoupled in olig1null mice. J. Neurosci. 25, 1354-1365. doi: 10.1523/JNEUROSCI.3034-04. 2005

Yamashita, T., Miyamoto, Y., Bando, Y., Ono, T., Kobayashi, S., Doi, A., et al. (2017). Differentiation of oligodendrocyte progenitor cells from dissociated monolayer and feeder-free cultured pluripotent stem cells. PLOS ONE 12:e0171947. doi: 10.1371/journal.pone.0171947

Yao, Z.-F., Wang, Y., Lin, Y.-H., Wu, Y., Zhu, A.-Y., Wang, R., et al. (2017). Transplantation of PDGF-AA-overexpressing oligodendrocyte precursor cells promotes recovery in rat following spinal cord injury. Front. Cell. Neurosci. 11:79. doi: 10.3389/fncel.2017.00079

Yoneda, K., Yamamoto, N., Fau, A., Sobue, K., Fujita, M., Mase, M., et al. (2001). Regulation of aquaporin-4 expression in astrocytes. Brain Res. Mol. Brain Res. 89, 94-102. doi: 10.1016/S0169-328X(01)00067-5

Zhang, P., Chebath, J., Lonai, P., and Revel, M. (2004). Enhancement of oligodendrocyte differentiation from murine embryonic stem cells by an activator of gp130 signaling. Stem Cells 22, 344-354. doi: 10.1634/stemcells.223-344

Zhu, B., Zhao, C., Young, F. I., Franklin, R. J. M., and Song, B. (2007). Isolation and long-term expansion of functional, myelinating oligodendrocyte progenitor cells from neonatal rat brain. Curr. Protoc. Stem Cell Biol. 31, 2D.17.1-2D.17.15. doi: $10.1002 / 9780470151808 . s c 02 d 17 s 31$

Conflict of Interest Statement: The authors declare that the research was conducted in the absence of any commercial or financial relationships that could be construed as a potential conflict of interest.

Copyright (๑) 2017 Dolci, Pino, Berton, Gonzalez, Braga, Fumagalli, Bonfanti, Malpeli, Pari, Zorzin, Amoroso, Moscon, Rodriguez, Fumagalli, Bifari and Decimo. This is an open-access article distributed under the terms of the Creative Commons Attribution License (CC BY). The use, distribution or reproduction in other forums is permitted, provided the original author(s) or licensor are credited and that the original publication in this journal is cited, in accordance with accepted academic practice. No use, distribution or reproduction is permitted which does not comply with these terms. 